\title{
A FOOD PREDICTIVE CUE MUST BE ATTRIBUTED WITH INCENTIVE SALIENCE FOR IT TO INDUCE C-FOS MRNA EXPRESSION IN CORTICO-STRIATAL-THALAMIC BRAIN REGIONS
}

\author{
Shelly B. Flagel ${ }^{1}$, Courtney M. Cameron ${ }^{2}$, Kristen N. Pickup ${ }^{3}$, Stanley J. Watson ${ }^{4}$, Huda \\ Akil $^{4}$, and Terry E. Robinson ${ }^{3}$ \\ ${ }^{1}$ Department of Psychiatry, University of Michigan, United States \\ ${ }^{2}$ Department of Psychology, University of North Carolina, United States \\ ${ }^{3}$ Department of Psychology and Neuroscience Program, University of Michigan, United States \\ ${ }^{4}$ Molecular and Behavioral Neuroscience Institute, University of Michigan, United States
}

\section{Abstract}

Cues associated with rewards acquire the ability to engage the same brain systems as rewards themselves. However, reward cues have multiple properties. For example, they not only act as predictors of reward capable of evoking conditional responses (CRs), but they may also acquire incentive motivational properties. As incentive stimuli they can evoke complex emotional and motivational states. Here we sought to determine whether the predictive value of a reward cue is sufficient to engage brain reward systems, or whether the cue must also be attributed with incentive salience. We took advantage of the fact that there are large individual differences in the extent to which reward cues are attributed with incentive salience. When a cue (conditional stimulus, CS) is paired with delivery of food (unconditional stimulus, US), the cue acquires the ability to evoke a CR in all rats; that is, it is equally predictive and supports learning the CS-US association in all. However, only in a subset of rats is the cue attributed with incentive salience, becoming an attractive and desirable incentive stimulus. We used in situ hybridization histochemistry to quantify the ability of a food cue to induce c-fos mRNA expression in rats that varied in the extent to which they attributed incentive salience to the cue. We found that a food cue induced c-fos mRNA in the orbitofrontal cortex, striatum (caudate and nucleus accumbens), thalamus (paraventricular, intermediodorsal and central medial nuclei) and lateral habenula, only in rats that attributed incentive salience to the cue. Furthermore, patterns of "connectivity" between these brain regions differed markedly between rats that did or did not attribute incentive salience to the food cue. These data suggest that the predictive value of a reward cue is not sufficient to engage brain reward systems - the cue must also be attributed with incentive salience.

(C) 2011 IBRO. Published by Elsevier Ltd. All rights reserved.

Corresponding Author: Shelly B. Flagel, Ph.D., Molecular and Behavioral Neuroscience Institute, University of Michigan, 205 Zina Pitcher Place, Ann Arbor, MI, Phone: 734936 2033, Fax: 734647 4130, sflagel@umich.edu.

Publisher's Disclaimer: This is a PDF file of an unedited manuscript that has been accepted for publication. As a service to our customers we are providing this early version of the manuscript. The manuscript will undergo copyediting, typesetting, and review of the resulting proof before it is published in its final citable form. Please note that during the production process errors may be discovered which could affect the content, and all legal disclaimers that apply to the journal pertain. 


\section{Keywords}

sign-trackers; goal-trackers; incentive salience; c-fos; mesocorticolimbic; motive circuit

\section{INTRODUCTION}

Cues in the environment (conditional stimuli, CSs) associated with rewards (unconditional stimuli, USs) can come to influence behavior in a number of different ways. Perhaps best known is the ability of a CS to evoke simple conditional responses (CRs) that often prepare an organism for consumption of the US, such as salivation or conditioned insulin release, in the case of a food reward (Pavlov, 1927; Woods et al., 1970; Zener, 1937). But cues predictive of an outcome also play an important role in learning and making decisions about what actions are most advantageous in a given situation (Bindra, 1974; Toates, 1998; Dickinson and Balleine, 2002). Furthermore, such cues can come to act as incentive stimuli and become attractive and desired in their own right, if they are attributed with incentive salience (Berridge, 2001; Cardinal et al., 2002). If reward cues are attributed with incentive salience they may be especially effective in motivating maladaptive behaviors, including, overeating (Schachter, 1968; Grilo et al., 1989; Sobik et al., 2005), gambling (Potenza et al., 2003; Kushner et al., 2007), risky sexual behavior (for review see O'Donohue and Plaud, 1994) and drug abuse (for reviews see Childress et al., 1993; O'Brien, 2005). There has been considerable interest, therefore, in identifying brain systems that mediate the effects of reward cues on behavior.

There is now abundant evidence in both humans and non-human animals that different classes of reward cues (e.g., food, sex or drug cues) engage highly overlapping brain systems. This reward or "motive circuit" includes mesocorticolimbic dopamine pathways as well as other cortico-striatal-thalamic loops (Childress et al., 1999; Ikemoto, 2010; Jentsch and Taylor, 1999; Kalivas and Volkow, 2005; Kelley et al., 2005a; Weiss, 2005; Schiltz et al., 2007; Zellner and Ranaldi, 2010). However, it is not clear from previous studies exactly what properties of a reward cue are responsible for activating these brain regions. Is the predictive relationship with a US, which supports the ability of a CS to evoke a CR, sufficient to engage this system? Or, must the CS also be attributed with incentive salience? It is not easy to parse these different properties of reward cues because they are usually acquired together (Berridge and Robinson, 2003; Berridge, 2007). Nevertheless, in a series of recent studies using rats, we have shown that it is possible to dissociate the predictive and incentive motivational properties of reward cues through the study of individual differences (Flagel et al., 2007; Flagel et al., 2008b; Flagel et al., 2011; Robinson and Flagel, 2009).

When a spatially discrete CS is presented prior to food delivery the CS comes to evoke a CR in all rats - that is, it is equally predictive and supports learning the CS-US association in all. However, the CS is attributed with incentive salience only in a subset of rats. This is indicated by the observation that only in some rats does the CS itself (1) become attractive, eliciting approach towards it (Flagel et al., 2007; Flagel et al., 2008a), (2) desired, in that animals will work to get it (Flagel et al., 2011; Robinson and Flagel, 2009), and (3) effective in motivating renewed seeking for the reward after extinction of an instrumental response (Saunders and Robinson, 2010; Yager and Robinson, 2010). Animals prone to attribute incentive salience to a reward cue are called "sign-trackers" (STs), a term derived from their propensity to approach the cue or "sign" that signals impending reward delivery (Brown and Jenkins, 1968; Hearst and Jenkins, 1974). In other individuals a food cue is equally predictive and equally effective in evoking a CR, but in these animals the CR is not directed towards the cue itself, but to the location of impending reward delivery, and in these rats the cue is also not a very effective conditioned reinforcer (Flagel et al., 2011; Robinson and 
Flagel, 2009). These animals are called "goal-trackers" (GTs), a term derived from their propensity to approach the location of reward delivery (Boakes, 1977). Thus, the cue (CS) serves as an equally effective predictor in STs and GTs, and both STs and GTs learn the CSUS association, but only in STs does it function as a potent incentive stimulus (Flagel et al., 2011; Robinson and Flagel, 2009).

We have taken advantage of this natural individual variation in the propensity to attribute incentive salience to a reward cue to parse the psychological and neurobiological processes underlying stimulus-reward learning and motivated behavior (Flagel et al., 2007; Flagel et al., 2011; Robinson and Flagel, 2009). Most recently, we utilized this model to study the role of dopamine in stimulus-reward learning (Flagel et al., 2011). We demonstrated that learning a sign-tracking $\mathrm{CR}$ requires dopamine but learning a goal-tracking $\mathrm{CR}$ does not (also see Danna and Elmer, 2010). Furthermore, the acquisition of a sign-tracking CR is associated with the transfer of a phasic dopamine response from the US to the CS, whereas learning a goal-tracking CR is not (Flagel et al., 2011). Thus, dopamine is not required for all forms of learning in which reward cues become effective predictors (Schultz et al., 1997; Waelti et al., 2001), but acts selectively in a form of stimulus-reward learning in which incentive salience is attributed to reward cues (Flagel et al., 2011). Here, we used the same logic to examine more broadly, what brain regions are "engaged" when the cue has predictive value (i.e. as in GTs and STs) relative to when it also has incentive value (i.e. only for STs). To do this we used in situ hybridization histochemistry to quantify the ability of a food cue to induce c-fos mRNA expression in rats classed as STs or GTs, and in a control group that received unpaired presentations of the CS and US. We focused on those brain regions previously reported to be engaged' by reward cues - the so-called "motive circuit" that includes the prefrontal cortex, dorsal and ventral striatum, thalamus, habenula and amygdala (Cardinal et al., 2002; Ikemoto, 2010; Kalivas and Volkow, 2005; Weiss, 2005; Schiltz et al., 2007). We report that a food cue induced c-fos mRNA expression in these brain regions only in rats that attributed incentive salience to the cue.

\section{MATERIALS AND METHODS}

\section{Subjects}

Male Sprague-Dawley rats (Charles River, Wilmington, MA, USA) weighing 250-300 g upon arrival were used. Rats were housed individually in hanging acrylic cages $(8 \times 8 \times 9$ $\mathrm{cm}$ ) and kept on a 12-hr light/12-hr dark cycle (lights on at $0800 \mathrm{hr}$ ) in a temperature and humidity controlled colony room. Food and water were available ad libitum for the duration of the study. Procedures were approved by the University Committee on the Use and Care of Animals.

\section{Pavlovian conditioning}

Pavlovian training was conducted using an autoshaping procedure described previously (Flagel et al., 2007). All training sessions were conducted between 1100 and $1600 \mathrm{hr}$. Standard $(22 \times 18 \times 13 \mathrm{~cm})$ test chambers (Med Associates Inc., St. Albans, VT, USA) were located inside a sound-attenuating cabinet with a ventilating fan to mask background noise. For Pavlovian training each chamber had a food cup located in the center of one wall, $3 \mathrm{~cm}$ above a stainless steel grid floor. A retractable lever was located $2.5 \mathrm{~cm}$ to the left of the food cup and a red house light located at the top of the wall opposite the food cup remained illuminated for the duration of each session.

Banana-flavored food pellets (Bio-Serv, Frenchtown, NJ) were placed into the rats' home cages for 2 days prior to training to familiarize the animals with this food, which served as the US. Two pre-training sessions were conducted, consisting of the delivery of 50 food 
pellets on a variable time 30 -s schedule (25-min session), and it was determined whether the rats reliably retrieved the food pellets. For rats in the Paired groups $(n=45)$ each daily Pavlovian training session, which followed pre-training, consisted of 25 trials in which the lever (CS) was inserted into the chamber for $8 \mathrm{~s}$ and immediately following its retraction a 45-mg food pellet (US) was delivered into the food cup, using a variable time $90 \mathrm{~s}$ schedule (i.e. one presentation of the CS occurred on average every $90 \mathrm{~s}$, but the actual time between CS presentations varied randomly between 30 and $150 \mathrm{~s}$ ). When the lever was inserted, the slot through which it protruded was simultaneously illuminated by a LED located behind the slot. Note that no response was required for the rat to receive reward, and that the animals were not food deprived. Rats in the Unpaired Group (UN, n=15) received pseudorandom CS and US presentations during each session. Pavlovian training was conducted over 7 consecutive days (Days 1-7).

The following events were recorded using Med Associates software: (1) number of lever-CS contacts, (2) latency to the first lever-CS contact, (3) number of food cup entries during lever-CS presentation, (4) latency to the first food cup entry following lever-CS presentation, and (5) number of food cup entries during the inter-trial interval (ITI). From these measures a "Pavlovian Conditioned Approach" (PCA) score was calculated using the following formula: ((Response Bias + Probability + Contact Latency)/3)). Where Response Bias $=($ lever contacts - magazine entries $) /($ lever contacts + magazine entries $) ;$ Probability $=$ (lever contact probability - magazine entry probability $)$; and Contact Latency $=(-$ lever contact latency - magazine entry latency))/8 sec. The final PCA score was obtained by averaging scores from sessions 6-7. With this index a score of +1 indicates that all responses were directed towards the lever-CS, a score of -1 indicates that all responses were directed towards the food cup, and a score of zero signifies that responses were directed equally to both places.

\section{Test day: Re-exposure to the CS}

The day following Pavlovian training the test chambers were reconfigured such that the pellet dispenser and food magazine were removed and only the houselight and retractable lever were present in the original positions. To minimize the influence of contextual cues all rats were placed into the reconfigured chambers for $30 \mathrm{~min}$ on each of the next 3 consecutive days (Days 8-10), during which time the houselight was illuminated but the lever remained retracted. On Day 11, rats were placed into the chambers, the houselight was illuminated, and following a 5-min habituation period the illuminated lever-CS was inserted into the cage for $2 \mathrm{sec}$ a total of 10 times (once per minute). Note that no food was delivered during this test and, as in training, presentation of the lever-CS was non-contingent, i.e., it was independent of the animals' behavior. After the last lever-CS presentation the rats were left in the chamber undisturbed for an additional $30 \mathrm{~min}$, after which time they were removed and immediately decapitated. Thus, animals were sacrificed approximately 40 minutes after the first lever-CS presentation. This time point was chosen because it falls within the range of those previously found for optimal stimulus-induced c-fos mRNA expression (Kabbaj and Akil, 2001; Ostrander et al., 2003).

\section{In situ hybridization: c-fos mRNA expression}

Tissue processing-After decapitation the brains were rapidly removed, frozen in isopentane $\left(-30^{\circ} \mathrm{C}\right.$ to $\left.-40^{\circ} \mathrm{C}\right)$, and then stored at $-80^{\circ} \mathrm{C}$ until further processing. Coronal brain sections $(10 \mu \mathrm{m}$ ) were cut on a cryostat (at 200- $\mu \mathrm{m}$ intervals) and thaw mounted onto Superfrost/Plus slides (Fisher Scientific, Pittsburgh, PA, USA). Sections were obtained throughout the brain, beginning around $5.20 \mathrm{~mm}$ anterior to bregma and ending around $-9.30 \mathrm{~mm}$ posterior to bregma (Paxinos and Watson, 1998). Slides were stored at $-80^{\circ} \mathrm{C}$ 
until in situ hybridization was performed as previously described (Kabbaj et al., 2000; Flagel et al., 2007).

In situ hybridization-Briefly, post-fixed sections were hybridized with a ${ }^{35} \mathrm{~S}$-labeled cRNA probe produced using standard in vitro transcription methodology. The c-fos probe was a 783-base-pair fragment directed against the rat c-fos mRNA. The probe was diluted in hybridization buffer and brain sections were coverslipped and incubated overnight at $55^{\circ} \mathrm{C}$. Following post-hybridization rinses and dehydration, slides were apposed to Kodak Biomax MR film (Eastman Kodak, Rochester, NY, USA). Sections were exposed for approximately 12 weeks. The specificity of the hybridization signal was confirmed by control experiments using sense probes.

Quantification of radioactive signal-Autoradiograms were captured and digitized using Microtek ScanMaker 1000XL (Fontana, CA) and the scanner was driven by Lasersoft Imaging (SilverFast) software (Sarasota, FL). The magnitude of the signal from the hybridized ${ }^{35}$ S-cRNA probe was determined using National Institutes of Health Image J software. A template was generated and used for each region of interest. In addition, a macro was used which enabled signal above background [ $(3.5 \times$ standard deviation $)+$ mean of the background] to be automatically determined. The integrated optical density (IOD) of these signal pixels was obtained by multiplying the size of the area quantified by the mean signal intensity. The person quantifying was blind to group assignments.

Optical density measurements were taken from the left and right hemispheres of at least four brain sections per animal for each region of interest. Images were quantified across multiple anterior-posterior (A-P) levels, as indicated by distance from bregma, and a mean IOD value was generated for each animal and brain region, and values for the left and right hemisphere averaged. If there was no effect of A-P level (i.e. P $>0.05$ ) the data were collapsed and averaged across levels. Oftentimes, a specific A-P level(s) was chosen for analysis if there was increased variance at other levels due to a small sample size, because it was rare to have all animals represented across all A-P levels. Also, if there was a large effect of A-P level on c-fos mRNA expression the analysis was confined to the appropriate A-P level(s), as indicated below.

For regions of interest that did not have a strong signal or were difficult to identify, adjacent sections underwent further processing and images were overlaid prior to quantification. To identify nuclei of the amygdala, an acetylcholinesterase stain (see Hedreen et al., 1985; Burghardt and Wilson, 2006) was used (Figure 1A); and to distinguish sub-regions of the habenula and thalamus adjacent sections were processed for vesicular glutamate transporter-2 (vglut2) mRNA using in situ hybridization techniques (Figure 1B). A "Modified Kluver" stain (adapted from Kluver and Barrera, 1953) consisting of Luxol Fast Blue, Eosin and Cresyl Violet was used to identify landmarks and help distinguish between the core and the shell of the nucleus accumbens.

\section{Statistics}

Linear mixed-effects models (SPSS 18.0; Verbeke and Molenberghs, 2000) were used to analyze the PCA scores during the 7 days of training. One-way ANOVAs were used to examine group differences on the last day of Pavlovian training (Figure 2) and for all of the c-fos mRNA data (Figures 4-7). Significance was set at $P \leq 0.05$ and when significant main effects were found post-hoc comparisons were made using Fisher's Protected Least Significant Difference (PLSD) test.

The relationship between c-fos expression patterns and behavior upon re-exposure to the CS was examined using correlation $\mathrm{Z}$ tests with a $95 \%$ confidence interval. The relationship 
between c-fos expression patterns across brain regions for each group was examined using correlation $\mathrm{Z}$ tests and then corrected for false discovery rate using Bioconductor "qvalue" package (http://www.bioconductor.org). The proportion of false positives (i.e., "q-value") was generated from the list of $p$-values and data were only considered significant when there was less than a $10 \%$ chance for false positives to occur (Figure 8 and Table 1). The same A$\mathrm{P}$ levels as indicated below for each brain region were used for the correlation analyses.

\section{RESULTS}

\section{Pavlovian conditioning}

Rats were classed as sign-trackers (STs) or goal-trackers (GTs) based on their PCA score averaged over the last two days of Pavlovian training (days 6-7). Rats with an average approach index of $\geq 0.3$ were designated STs $(n=6$, average PCA score $=+0.6)$ and those with an index score of $\leq-0.3$ were designated GTs $(n=10$, average PCA score $=-0.8)$. Rats with an intermediate' score were not utilized for this study. Rats in the UN group had a PCA score of $\leq 0.5$ or $\geq-0.5$ (i.e. did not show a strong preference for either the lever-CS or the food-cup; $n=9$, average PCA score $=-0.2$ ). Thus, a maximum of 25 animals are included in the behavioral and neurobiological data presented below.

As shown in Figure 2, STs exhibited a clear preference for the lever-CS by the third day of training and GTs showed preference for the food cup during all seven training sessions. It is likely that GTs showed a preference for the food cup early in training because of the two pre-training' sessions, when all animals were required to retrieve pellets from the food cup. Rats in the UN group did not learn either a ST or GT conditional response, although they tended to approach the food cup more than the lever-CS, but this behavior did not change over time as a function of training, and was not as strong as that in GTs. Overall, for PCA scores, there was a significant effect of group $\left(\mathrm{F}_{(2,30)}=251.0, \mathrm{P}<0.0001\right)$, a significant effect of day $\left(\mathrm{F}_{(6,34)}=3.2, \mathrm{P}=0.01\right)$, and a significant group $\times$ day interaction $\left(\mathrm{F}_{(12,35)}=4.7\right.$, $\mathrm{P}<0.0001)$. When the groups were analyzed independently for this measure, only for STs was there a significant effect of day $\left(\mathrm{F}_{(6,40)}=9.0, \mathrm{P}<0.0001\right)$. However, both STs and GTs showed evidence of learning their respective behaviors, as there was a significant effect of day for other indices of sign-tracking and goal-tracking behavior (e.g. contacts with the lever or food cup, latency to approach, etc.) when the groups were analyzed independently (data not shown).

By the last day of training (Day 7) there was a large difference in behavior between groups (Figure 3). STs showed a greater probability to approach the lever-CS (Figure 3A, $\mathrm{F}_{(2,22)}=124.0, \mathrm{P}<0.0001$ ), an increased number of lever-CS contacts (Figure 3B, $\left.\mathrm{F}_{(2,22)}=32.7, \mathrm{P}<0.0001\right)$, and approached the lever-CS more rapidly than GTs or rats in the $\mathrm{UN}$ group (Figure $3 \mathrm{C}, \mathrm{F}_{(2,22)}=42.2, \mathrm{P}<0.0001$ ). In contrast, GTs showed increased probability to approach the food cup (Figure $3 \mathrm{D}, \mathrm{F}_{(2,22)}=120.4$, $\mathrm{P}<0.0001$ ), a greater number of head entries (contacts) into the food cup during lever-CS presentation (Figure 3E, $\mathrm{F}_{(2,22)}=33.7, \mathrm{P}<0.0001$ ) and approached the food cup more rapidly (Figure $3 \mathrm{~F}, \mathrm{~F}_{(2,22)}=25.3$, $\mathrm{P}<0.0001$ ) than the other two groups. Thus, as we have reported previously (Flagel et al., 2007; Flagel et al., 2008a; Flagel et al., 2008b; Flagel et al., 2011; Robinson and Flagel, 2009), there is considerable individual variation in the topography of the CR that develops in this situation. Some rats learn to preferentially approach the CS whereas others learn to approach the location where food will be delivered.

\section{Test day: Re-exposure to the CS}

When the lever-CS was presented under extinction conditions, after 3 days of habituation to the test context, some STs approached and contacted it, even though it was presented very 
briefly, for only $2 \mathrm{sec}$. However, other STs did not contact the lever, and correlational analyses revealed no significant relationship between the number of lever contacts upon reexposure to the CS for STs and the expression of c-fos mRNA in any brain region examined $\left(r^{2} \leq 0.34, \mathrm{P} \geq 0.25\right)$. None of the GTs contacted the lever-CS during this test session.

\section{In situ hybridization: c-fos mRNA expression}

Prefrontal Cortex-There were no significant group differences in the prelimbic, infralimbic or anterior cingulate cortices at any A-P level, although there was a nonsignificant $\left(\mathrm{F}_{(2,22)}=2.2, \mathrm{P}=0.14\right)$ trend for greater $\mathrm{c}$-fos mRNA expression in STs in the rostral (3.1 $\mathrm{mm}$ anterior to bregma) portion of the prelimbic area, which is evident in Figure 4. There were no significant group differences in the orbitofrontal cortex at the most rostral levels (data not shown), but at A-P level $3.1 \mathrm{~mm}$ anterior to bregma STs showed significantly greater c-fos mRNA expression than GTs or the UN group, which did not differ from one another $\left(\mathrm{F}_{(2,22)}=3.6, \mathrm{P}=0.04\right.$; Figure 4$)$.

Striatum and Lateral Septum-The nucleus accumbens was divided into the core and shell subdivisions and there were significant group differences in c-fos mRNA expression across A-P levels $1.6 \mathrm{~mm}$ and $1.2 \mathrm{~mm}$ anterior to bregma in both the core $\left(\mathrm{F}_{(2,22)}=3.3\right.$, $\mathrm{P}=0.05)$ and the shell $\left(\mathrm{F}_{(2,22)}=4.4, \mathrm{P}=0.03\right)$. STs showed greater $\mathrm{c}$-fos mRNA expression in both of these regions relative to GTs or the UN group, which did not differ from one another (Figure 5A). The caudate-putamen was divided into medial and lateral as well as dorsal and ventral subdivisions and quantified at both anterior (1.6 $\mathrm{mm}$ and $1.2 \mathrm{~mm}$ to bregma) and more posterior $(0.8 \mathrm{~mm}$ and $0.4 \mathrm{~mm}$ to bregma) A-P levels. In STs, presentation of the lever-CS increased c-fos mRNA expression in the ventrolateral portion of the striatum at both rostral $\left(\mathrm{F}_{(2,22)}=3.9, \mathrm{P}=0.04\right)$ and more posterior $\left(\mathrm{F}_{(2,22)}=7.0, \mathrm{P}=0.005\right.$; Figure 5A \& B) levels. Presentation of the lever-CS also induced greater c-fos mRNA expression in STs in the more posterior portions of the dorsomedial $\left(\mathrm{F}_{(2,22)}=6.9, \mathrm{P}=0.005\right)$, dorsolateral $\left(\mathrm{F}_{(2,22)}=6.7, \mathrm{P}=0.005\right)$ and ventromedial striatum $\left(\mathrm{F}_{(2,22)}=11.7, \mathrm{P}=0.0003\right.$; see Figure $\left.5 \mathrm{~B}\right)$, but there were no significant group differences in these latter three subregions at the more anterior A-P levels of the caudate-putamen (Figure 5A). In addition, STs showed greater cfos mRNA expression in the lateral septum (Figure 5A, $\mathrm{F}_{(2,18)}=9.2, \mathrm{P}=0.002$ ).

Habenula and Thalamus-Presentation of the lever-CS evoked greater c-fos mRNA expression in the lateral habenula (A-P levels -3.3 and $-3.6 \mathrm{~mm}$ posterior to bregma; $\mathrm{F}_{(2,19)}$ $=6.6, \mathrm{P}=0.007)$ in $\mathrm{STs}$ relative to GTs or the $\mathrm{UN}$ group, which did not differ from one another, and there was a similar trend in the medial habenula (Figure $6, \mathrm{~F}_{(2,19)}=3.0$, $\mathrm{P}=0.07)$.

STs also had greater c-fos mRNA expression than the other two groups in the anterior portion of the paraventricular nucleus of the thalamus (Figure 6, A-P level $-3.14 \mathrm{~mm}$ posterior to bregma; $\mathrm{F}_{(2,21)}=7.2, \mathrm{P}=0.004$ ), but not at more caudal levels (e.g., $-4.16 \mathrm{~mm}$ to bregma; data not shown), and similar group differences were seen in the intermediodorsal nucleus $\left(\mathrm{F}_{(2,22)}=3.4, \mathrm{P}=0.05\right)$ and the central medial nucleus of the thalamus (Figure 6, $\left.\mathrm{F}_{(2,22)}=3.6, \mathrm{P}=0.04\right)$. There were no significant group differences in c-fos mRNA expression in the paracentral nucleus or the centrolateral nucleus of the thalamus (Figure 6).

Amygdala-Although there was a tendency for greater c-fos mRNA expression in STs in the three subregions of the amygdala analyzed, group differences were not statistically significant (Figure 7). We speculate that significant effects were precluded by increased variance due to technical difficulties in identifying the boundaries of the subnuclei and the smaller number of samples for this region. 
Other Brain Regions of Interest-Other brain regions that were quantified and analyzed for group differences in c-fos mRNA expression included the primary motor cortex, sensory cortical areas, piriform cortex, claustrum, medial geniculate nucleus, olfactory tubercle, periaqueductal gray and the superior colliculus. The only significant group difference was in the primary motor cortex $\left(\mathrm{F}_{(2,19)}=3.7, \mathrm{P}=0.04\right)$.

Connectivity Between Brain Regions-As shown in Figure 8, the pattern of "connectivity" between brain regions, as indicated by significant interregional correlations, varied as a function of group. Given the number of correlations analyzed, we were conservative with our approach in determining what was significant and only those correlations that had less than a $10 \%$ chance of revealing false positives are presented and discussed. There was a positive correlation between levels of c-fos mRNA expression in the shell and core of the nucleus accumbens for GTs and the unpaired group. Interestingly, however, STs did not show a positive correlation in c-fos expression between subregions of the accumbens, but there was a strong correlation between the core of the accumbens and dorsomedial portion of the posterior caudate. Moreover, unlike the other two groups, in STs there was a strong negative correlation between both the paraventricular and intermediodorsal nuclei and the shell of the nucleus accumbens. The only other significant negative correlation was detected in GTs, between the shell and dorsomedial portion of the posterior caudate. Goal-trackers also showed a significant positive correlation between the paraventricular nucleus of the thalamus and orbitofrontal cortex; thus, they were the only group to show evidence of a thalamocortical association. A more detailed summary of the correlational data are included in Table 1. Taken together, these data highlight the extent to which different neural systems are engaged by a reward cue in STs vs. GTs.

\section{DISCUSSION}

It is well established that mesocorticolimbic and cortico-striatal-thalamic brain regions that form a so-called "motive circuit" are engaged in response to cues associated with natural rewards (food, sex) and drugs of abuse (Childress et al., 1999; Kalivas and Volkow, 2005; Kelley et al., 2005a), and even to reward cues presented outside of conscious awareness (Childress et al., 2008). Together, these brain regions mediate the integration of learning, emotion and arousal to produce motivated behavior (Koob and Volkow, 2010; Schiltz et al., 2007). However, reward cues have multiple properties (e.g. learned associative prediction, hedonic impact, incentive motivation) (Berridge and Robinson, 2003; Smith et al., 2011), and, until now, it was not known which particular feature of a reward cue is most effective in engaging these brain regions because these properties of reward cues are usually acquired together and difficult to parse. Here we took advantage of individual variation in the propensity to attribute incentive salience to a food cue to dissociate its predictive and incentive properties, and report that the learned predictive properties of a reward cue are not sufficient to fully engage this "motive circuit". Instead, the cue must also be attributed with incentive motivational properties (i.e. incentive salience). Moreover, the pattern of interregional "connectivity" within this broadly distributed network varies greatly between rats that do or do not attribute incentive salience to the cue.

In almost every brain region examined, a food cue that induced c-fos mRNA expression did so in STs, but not GTs, relative to rats that received unpaired CS-US presentations. To minimize any behavioral differences on the test day that might affect c-fos mRNA levels and confound interpretation of the results, we presented the lever only 10 times, and very briefly, at a duration of $2 \mathrm{sec}$ for each presentation. However, there were still behavioral differences during the cue re-exposure session. Some of the STs continued to approach and contact the lever; whereas none of the GTs came into contact with the lever during the test session. To examine whether induction of c-fos mRNA was due merely to differences in 
motor activity, we conducted correlational analyses between c-fos mRNA levels and lever contacts for STs, and found no significant relationship in any brain region examined. In addition, the fact that there were no significant group differences in c-fos mRNA expression in anterior portions of the dorsal striatum and only minimal differences in the primary motor cortex supports the notion that the group differences are not attributable to differences in lever-directed motor behavior. Although it is possible that the differences in c-fos expression could be due to other factors (e.g. stress) that are not specifically associated with reward learning mechanisms, this is unlikely. All three groups were exposed to the same Pavlovian training procedures followed by novel context habituation and subsequently the same number of CS presentations prior to sacrifice. Moreover, there were no significant differences in c-fos mRNA expression in the amygdala, which would have been expected if these were indeed "stress effects" (Cullinan et al., 1995). Thus, given that the major difference between STs and GTs is the extent to which the cue acquired incentive motivational properties, we conclude that group differences in c-fos mRNA expression patterns most likely indicate that these brain regions are especially important in mediating incentive motivational processes. This is not to say that some of these brain regions are not involved in other components of stimulus-reward learning (e.g., hedonics or associative learning; Faure et al., 2010; Smith et al., 2009; Smith et al., 2011), but at this level of analysis they appear to be especially sensitive to reward cues that have been attributed with incentive salience.

Among the most interesting findings reported here are the apparent differences in interregional "connectivity" between groups, as indicated by the extent to which levels of cfos expression are highly correlated between different brain regions (Figure 8). Although we readily acknowledge that the functional significance of the reported correlations is highly speculative, we did use very conservative statistical tests to control for random effects, and therefore presume that they reflect reliable relationships. Thus, we suggest that the distinct patterns of "connectivity" in STs and GTs highlight the extent to which different neural systems are engaged when a reward cue has predictive value (GTs and STs) versus when it also has incentive value (STs). Of course, more detailed molecular and anatomical studies are needed to determine the extent to which these functionally-linked areas truly represent distinct "circuits".

Very little is known about the psychological and neurobiological processes regulating goalvs. sign-tracking behavior. However, in light of our recent findings elucidating the role of dopamine in these CRs (Flagel et al., 2011; also see Danna and Elmer, 2010), we speculate that these are very distinct processes, and that GTs use more of a "cognitive" learning strategy than that used by STs, and our current results further support this hypothesis. GTs were the only group to show thalamocortical and corticostriatal associations; possibly indicating greater top-down executive control of their behavior. In agreement, Shiltz et al. (2007) previously reported increased cortical engagement of the striatum upon presentation of food cues, and it has been postulated that these corticostriatal connections mediate goaldirected behavior via conditioned inhibitory processes. Moreover, Dickinson and Balleine (2002) have argued that goal-directed behavior is not governed by dopamine-dependent Pavlovian incentive learning processes, but by dopamine-independent cognitive processes. We suggest, therefore, that for goal-trackers, these cognitive processes encode the CS with a sensory/perceptual representation of the reward and this produces CS-elicited approach to the location of impending reward delivery (Dickinson and Balleine, 2002). That is, for GTs, the CS is purely an "informational" stimulus, and is relatively devoid of incentive properties. In contrast, for sign-trackers, the CS acquires the properties of an incentive stimulus via dopamine-dependent Pavlovian incentive learning mechanisms, and its incentive properties make the CS itself attractive and desired, drawing the animal towards it, even though approaching the CS has no effect whatsoever on the probability of receiving the reward. 
This interpretation is consistent with our observation that in STs all of the strong interregional correlations were subcortical, suggesting a non-cognitive processing mechanism, and perhaps even an implicit process underlying this CR. We recognize that the food cup may have incentive properties for both STs and GTs (Mahler and Berridge, 2009), as both eventually go to the source of reward delivery; but in the current study we removed the food cup on the test day, and only presented the CS, to mitigate any influence it might have had and to isolate the incentive vs. predictive properties of the CS.

\section{Cortex}

Despite the lack of cortical involvement indicated by the interregional analyses in STs, we did find greater c-fos mRNA expression in these animals in the orbitofrontal cortex, and a trend in the same direction in the prelimbic region of the prefrontal cortex. These findings are in agreement with previous reports demonstrating a critical role of the orbitofrontal cortex in mediating the conditioned reinforcing properties of food reward cues in rats (Burke et al., 2008). Cocaine-associated cues capable of reinstating drug-seeking behavior in rats increase Arc mRNA levels in the orbitofrontal cortex (Zavala et al., 2008). Like c-fos, Arc is an immediate early gene that has been implicated in neuronal plasticity and learning and memory (Guzowski, 2002; Tzingounis and Nicoll, 2006) and more recently in the conditioned plasticity associated with incentive motivational effects of drug cues (Zavala et al., 2008). In the human neuroimaging literature, the orbitofrontal cortex has received much attention as a locus for cue reactivity and associated drug craving (Falck et al., 1990; Franklin et al., 2007; Schoenbaum and Shaham, 2008; McClernon et al., 2009). Moreover, structural and functional studies in both humans and non-human animals have implicated the orbitofrontal cortex in regulating impulsive behavior (Winstanley, 2007), and we have previously reported that STs show more impulsive actions than GTs (Flagel et al., 2010; Lovic et al., 2011). Thus, it is not surprising that STs-rats that attribute incentive salience to reward-associated cues-exhibit increased c-fos mRNA levels in the orbitofrontal cortex relative to rats that merely treat the signal as a predictor of reward (GTs) or rats that received unpaired CS-US presentations.

\section{Striatum}

The orbitofrontal cortex projects to both the dorsal and ventral striatum (Voorn et al., 2004; Schilman et al., 2008), areas where we also found pronounced group differences in c-fos mRNA levels. In STs (but not GTs) the food cue increased c-fos mRNA expression in the posterior portion of the dorsomedial, dorsolateral, ventromedial and ventrolateral dorsal striatum as well as the core and shell of the nucleus accumbens. In agreement, it has previously been shown that contextual cues associated with food increase the expression of a number of activity-regulated genes in both the dorsal and ventral striatum (Schiltz et al., 2007). The dorsal striatum receives the densest innervations from dopamine afferents (Fallon and Moore, 1978) and is known for its role in the selection and initiation of actions (Graybiel et al., 1994) and in mediating stimulus-response (habit) learning (White and McDonald, 2002; Everitt and Robbins, 2005; Everitt et al., 2008). Most relevant to the current findings, it has been reported that the dorsal striatum is involved in "nonhedonic" processes to modulate food motivation in humans. That is, food-related stimuli (without actual food consumption) have been shown to increase extracellular dopamine in the dorsal striatum in proportion to their ability to increase hunger and desire for food (Volkow et al., 2002). These and similar results with cocaine (Volkow et al., 2006) suggest that dopamine activity in the dorsal striatum incites behaviors necessary to procure the desired object, be it food or drugs. In agreement, a number of preclinical studies have demonstrated a role of the dorsal striatum in drug-seeking behavior and relapse (Ito et al., 2002; Fuchs et al., 2006; See et al., 2007), and the prevailing view is that this structure mediates the habitual nature of 
drug-seeking that underlies addiction (Tiffany, 1990; Robbins and Everitt, 1999; Everitt et al., 2008).

The ventral striatum, or nucleus accumbens, is considered the limbic-motor interface-a locus where learned associations of motivational significance are converted into action (Mogenson et al., 1980; Ito and Hayen, 2011). Projections from the prefrontal cortex to the accumbens have been recognized for providing properties of motivational salience and direction to goal-directed behavior, and this circuitry has been referred to as the "final common pathway" for eliciting drug-seeking behavior and contributing to relapse (Kalivas and Volkow, 2005). Indeed, there is abundant evidence supporting a role for the nucleus accumbens in the expression of conditioned emotional responses to cues and contexts associated with appetitive events, such as access to food or drugs (for reviews see Cardinal et al., 2002; Day and Carelli, 2007; Berridge, 2009), and these behaviors are mediated by both glutamate and dopamine signaling (e.g. Burns et al., 1994; Smith-Roe and Kelley, 2000; Di Ciano et al., 2001). Recent evidence suggests that, in addition to the mesocorticolimbic dopamine system, there also exist parallel glutamate-only and glutamatedopamine pathways (Yamaguchi et al., 2011), and these neurotransmitter systems interact to shape neural excitability and synaptic plasticity in striatal neurons (Di Filippo et al., 2009; Lovinger, 2010; Shiflett and Balleine, 2011; Surmeier et al., 2009) and to regulate behavior. The core of the nucleus accumbens depends on both dopaminergic and glutamatergic afferents and is believed to be the primary site mediating the expression of learned behaviors in response to predictive stimuli (Di Ciano and Everitt, 2001; Kelley, 2004). Further, it has been shown that the core, but not shell, is essential for cue-elicited, goal-directed behaviors, including cue-induced reinstatement of cocaine-seeking behavior (Fuchs et al., 2004; Ito et al., 2004). In contrast, reciprocal dopamine innervations from the ventral tegmental area to the shell of the accumbens contribute to learning associations between motivational events and environmental stimuli (Bassareo and Di Chiara, 1999; Sellings and Clarke, 2003). It has been suggested that neurons in the core encode the motivational value of reward cues to arouse behavior (Corbit and Balleine, 2011) and that the shell then uses this information to guide and modulate motivated behavior (Saddoris et al., 2011). Additional evidence implicates the core in the control of reward- or drug-seeking behavior by discrete cues and the shell over such behaviors by spatial and contextual information (Bossert et al., 2007; Chaudhri et al., 2010; Ito et al., 2008). In the present study STs exhibited enhanced c-fos mRNA in both subregions of the accumbens relative to GTs and rats in the unpaired group, suggesting that the core and shell may work in concert to mediate responses to discrete cues imbued with incentive motivational properties.

\section{Thalamus}

Another region considered a key target for dopaminergic projections is the thalamus (Sanchez-Gonzalez et al., 2005), a structure that has only relatively recently been implicated in appetitive associative learning and responsivity to reward cues (Asensio et al. 2010; Igelstrom et al., 2010; Hamlin et al., 2009). In humans, there is evidence to suggest dopaminergic regulation of thalamic involvement in reward expectation and reported associations between activity in the thalamus and dopamine D2 receptor availability in the dorsal striatum (Asensio et al. 2010). Moreover, in cocaine abusers, methylphenidate significantly increases dopamine in the thalamus and this increase is proportional to subjective ratings of craving (Volkow et al., 1997). We found that the food cue increased cfos mRNA levels in midline thalamic structures, including the paraventricular nucleus of the thalamus (PVT) and the intermediodorsal and centromedial nuclei, in STs (but not GTs). These findings are consistent with those of Schlitz et al (2007), who found increased immediate early gene expression in the midline nuclei of the thalamus in response to contextual food cues. The PVT has also recently been shown to be activated during cue- 
reward associative learning (Igelstrom et al., 2010). However, this is the first demonstration that this region may be engaged in a specific form of stimulus-reward learning--one in which incentive salience is assigned to discrete reward cues.

The connections of the PVT are consistent with such a role as it receives input from the amygdala, dopaminergic cells of the ventral tegmental area (VTA; Van der Werf et al., 2002), and from hypothalamic regions concerned with internal states (Groenewegen and Berendse, 1994; Van der Werf et al., 2002). The PVT also has glutamatergic projections to the shell of the nucleus accumbens that modulate dopamine release (Jones et al., 1989; Berendse and Groenewegen, 1990). Lesion studies have demonstrated a role of the PVT in both the conditioned and unconditioned properties of psychostimulant-induced behavioral sensitization (Young and Deutch, 1998), and a more recent study showed that the PVT mediates context-induced reinstatement of extinguished beer'-seeking behavior (Hamlin et al., 2009). In agreement, other studies have demonstrated induction of c-fos in the PVT following exposure to psychostimulants or drug-related contexts (Brown et al., 1992; Deutch et al., 1998; Rhodes and Crabbe, 2005). Moreover, fos protein is increased in both the accumbens and thalamus in anticipation of feeding, and lesions of the PVT attenuate anticipatory activity associated with mealtime (Nakahara et al., 2004; Kelley et al., 2005b; Mendoza et al., 2005). In the current study, we found that STs were the only group to show a negative relationship between the PVT and shell of the accumbens, but it is difficult to speculate on the meaning of this association the without knowing the specific cell types involved. Nonetheless, these findings support a role of the PVT in incentive motivational processes.

\section{Septum}

The lateral septum also receives dopaminergic input from the VTA (Deniau et al., 1980), and in turn projects to the nucleus accumbens and VTA to modulate dopaminergic activity (Louilot et al., 1989; Sheehan et al., 2004). Here we show that STs exhibit greater c-fos mRNA levels in the lateral septum relative to GTs and the UN group. The septum has historically been implicated in reward processing. Olds and Milner (1954) demonstrated that stimulation of this area was highly reinforcing and considered it to be critical for learning. In accordance with the present findings, Igelstrom et al. (2010) demonstrated differential c-fos expression in cue-reward learning in the lateral septum. It has also been shown that septal neurons are preferentially activated by cues that predict better outcomes (Thomas et al., 1991). Moreover, the lateral septum was recently identified as a critical relay point between the hippocampus and ventral tegmental area, a circuit that mediates reinstatement of drugseeking behavior by contextual stimuli (Luo et al., 2011). These findings are especially interesting given the positive correlation between the shell of the nucleus accumbens and the lateral septum in GTs, (but not STs), and the fact that GTs seem to use context to appropriately modify their behavior to a greater extent than STs (Morrow et al., 2011). Taken together, our findings support and expand those previously reported by demonstrating a more specific role for the lateral septum in stimulus-reward learning.

\section{Habenula}

Another region that is involved in regulating emotional behavior and recently has been implicated in reward learning is the habenula (Hikosaka, 2010). In the current study, we found increased cue-induced c-fos mRNA expression in STs in the lateral habenula and a similar trend in the medial habenula. The habenula is thought to act as a node to link the forebrain to midbrain regions and is one of the few brain regions known to influence both the dopamine and serotonin systems (Herkenham and Nauta, 1977; Hikosaka, 2010; Sutherland, 1982). Specifically, the habenula is thought to control motivated behavior and dopaminergic activity in the VTA via a relay in the rostromedial tegmental nucleus (RMTg; 
also known as the caudal tail of VTA; Jhou et al., 2009; Balcita-Pedicino et al., 2011; Hong et al., 2011). There is abundant evidence to suggest that lateral habenula neurons inhibit dopamine neurons. Electrical stimulation of this area inhibits activity of dopamine neurons in the substantia nigra and ventral tegmental area (Christoph et al., 1986; Ji and Shepard, 2007; Matsumoto and Hikosaka, 2007), and lesions of the habenula increase dopamine in the cerebral cortex and striatum (Nishikawa et al., 1986). It has been shown that animals with habenula lesions become hyperactive and have attentional deficits (Lee and Huang, 1988; Lecourtier and Kelly, 2005) and exhibit increased reward-seeking behavior (Friedman et al., 2010; Friedman et al., 2011). These effects are believed to be due to removal of the inhibition of dopamine neurons (Hikosaka, 2010). In contrast, electrical stimulation of the habenula attenuates reward-seeking behavior (Friedman et al., 2010; Friedman et al., 2011) and suppresses motor behavior via inhibition of dopamine-releasing neurons. Further, there are studies across species that suggest that the habenula plays a specific role in reinforcement learning by responding to the predictive nature of cues associated with either appetitive or aversive stimuli (Nishikawa et al., 1986; Schultz, 1998; Matsumoto and Hikosaka, 2007; Bromberg-Martin et al., 2010). For example, it has been shown that cocaine cues increase Fos protein in the lateral habenula in rats repeatedly injected with the drug (Falck et al., 1990; Brown et al., 1992; Franklin and Druhan, 2000). Thus, our findings again extend those previously reported by demonstrating a more specific role for the habenula in assigning incentive value to reward cues. Future studies will need to identify the specific cell types in which c-fos mRNA is expressed in order to determine the functional significance of these findings.

\section{Conclusions}

In conclusion, it is well known that cues associated with food or drug rewards can exert powerful effects on emotions and behavior and can evoke a motivational state of "craving" or "wanting" (Childress et al., 1999; Robinson and Berridge, 2000; Brody et al., 2002; Berridge and Robinson, 2003). Individuals who attribute reward cues with incentive salience find it more difficult to resist such cues and are thereby more susceptible to disorders of impulse control such as overeating and addiction. As we and others have previously shown, there are individual differences in the propensity to attribute incentive salience to a reward cue (Flagel et al., 2007; Flagel et al., 2008b; Mahler and Berridge, 2009; Anderson and Spear, 2011; Beckmann et al., 2011), and in the present study we took advantage of this natural variation to identify brain regions that are engaged' when a cue is or is not attributed with incentive salience. A so-called "motive circuit", comprised of mesocorticolimbic and cortico-striatal-thalamic systems, has been shown to be engaged by reward cues in both humans and non-human animals, and to play an important role in reward-related processes (Childress et al., 1999; Kalivas and Volkow, 2005; Kelley et al., 2005a). However, we report here that a discrete cue associated with food reward engages these regions, as indicated by cfos mRNA expression, only if that cue is attributed with incentive salience. Thus, we conclude that the primary function of these brain systems is specifically related to incentive motivational processes, not to all forms of associative learning whereby reward cues become effective predictors. Ongoing studies using the same animal model are investigating the circuitry activated by cues associated with drug reward, and together these studies may reveal patterns of neural activity that are specific to individuals that are prone to attribute incentive salience to reward cues and thus potentially have an increased propensity to develop disorders of impulse control, such as overeating, pathological gambling, or addiction.

\section{Acknowledgments}

We would like to thank James Dell'Orco for technical assistance with the behavioral studies and James Beals, Sharon Burke and Jennifer Fitzpatrick for assistance with the in situ hybridization studies and analysis. We would 
also like to thank Dr. Fan Meng for assistance with statistics. We thank Kent Berridge, Paul Meyer and Ben Saunders for comments on an earlier version of the manuscript. This research was supported by National Institute of Health grant R37-DA04294 to TER.

\section{References}

Anderson RI, Spear LP. Autoshaping in adolescence enhances sign-tracking behavior in adulthood: impact on ethanol consumption. Pharmacol Biochem Behav. 2011; 98:250-260. [PubMed: 21238477]

Asensio S, Romero MJ, Romero FJ, Wong C, Alia-Klein N, Tomasi D, Wang GJ, Telang F, Volkow ND, Goldstein RZ. Striatal dopamine D2 receptor availability predicts the thalamic and medial prefrontal responses to reward in cocaine abusers three years later. Synapse. 2010; 64:397-402. [PubMed: 20034014]

Balcita-Pedicino JJ, Omelchenko N, Bell R, Sesack SR. The inhibitory influence of the lateral habenula on midbrain dopamine cells: ultrastructural evidence for indirect mediation via the rostromedial mesopontine tegmental nucleus. J Comp Neurol. 2011; 519:1143-1164. [PubMed: 21344406]

Bassareo V, Di Chiara G. Differential responsiveness of dopamine transmission to food-stimuli in nucleus accumbens shell/core compartments. Neuroscience. 1999; 89:637-641. [PubMed: 10199600]

Beckmann JS, Marusich JA, Gipson CD, Bardo MT. Novelty seeking, incentive salience and acquisition of cocaine self-administration in the rat. Behav Brain Res. 2011; 216:159-165. [PubMed: 20655954]

Berendse HW, Groenewegen HJ. Organization of the thalamostriatal projections in the rat, with special emphasis on the ventral striatum. J Comp Neurol. 1990; 299:187-228. [PubMed: 2172326]

Berridge, KC. Reward learning: reinforcement, incentives and expectations. In: Medin, D., editor. Psychology of learning and motivation. Academic Press; 2001. p. 223-278.

Berridge $\mathrm{KC}$. The debate over dopamine's role in reward: the case for incentive salience. Psychopharmacology (Berl). 2007; 191:391-431. [PubMed: 17072591]

Berridge KC. 'Liking' and 'wanting' food rewards: brain substrates and roles in eating disorders. Physiol Behav. 2009; 97:537-550. [PubMed: 19336238]

Berridge KC, Robinson TE. Parsing reward. Trends Neurosci. 2003; 26:507-513. [PubMed: 12948663]

Bindra D. A motivational view of learning, performance, and behavior modification. Psychol Rev. 1974; 81:199-213. [PubMed: 4424766]

Boakes, R. Performance on learning to associate a stimulus with positive reinforcement. In: Davis, H.; Hurwitz, H., editors. Operant-Pavlovian Interactions. Hillsdale, NJ: Erlbaum; 1977. p. 67-97.

Bossert JM, Poles GC, Wihbey KA, Koya E, Shaham Y. Differential effects of blockade of dopamine D1-family receptors in nucleus accumbens core or shell on reinstatement of heroin seeking induced by contextual and discrete cues. J Neurosci. 2007; 27:12655-12663. [PubMed: 18003845]

Brody AL, Mandelkern MA, London ED, Childress AR, Lee GS, Bota RG, Ho ML, Saxena S, Baxter LR Jr, Madsen D, Jarvik ME. Brain metabolic changes during cigarette craving. Arch Gen Psychiatry. 2002; 59:1162-1172. [PubMed: 12470133]

Bromberg-Martin ES, Matsumoto M, Hikosaka O. Distinct tonic and phasic anticipatory activity in lateral habenula and dopamine neurons. Neuron. 2010; 67:144-155. [PubMed: 20624598]

Brown EE, Robertson GS, Fibiger HC. Evidence for conditional neuronal activation following exposure to a cocaine-paired environment: role of forebrain limbic structures. J Neurosci. 1992; 12:4112-4121. [PubMed: 1403102]

Brown PL, Jenkins HM. Auto-shaping of the pigeon's key-peck. J Exp Anal Behav. 1968; 11:1-8. [PubMed: 5636851]

Burghardt PR, Wilson MA. Microinjection of naltrexone into the central, but not the basolateral, amygdala blocks the anxiolytic effects of diazepam in the plus maze. Neuropsychopharmacology. 2006; 31:1227-1240. [PubMed: 16123750] 
Burke KA, Franz TM, Miller DN, Schoenbaum G. The role of the orbitofrontal cortex in the pursuit of happiness and more specific rewards. Nature. 2008; 454:340-344. [PubMed: 18563088]

Burns LH, Everitt BJ, Kelley AE, Robbins TW. Glutamate-dopamine interactions in the ventral striatum: role in locomotor activity and responding with conditioned reinforcement. Psychopharmacology (Berl). 1994; 115:516-528. [PubMed: 7871097]

Cardinal RN, Parkinson JA, Hall J, Everitt BJ. Emotion and motivation: the role of the amygdala, ventral striatum, and prefrontal cortex. Neurosci Biobehav Rev. 2002; 26:321-352. [PubMed: 12034134]

Chaudhri N, Sahuque LL, Schairer WW, Janak PH. Separable roles of the nucleus accumbens core and shell in context- and cue-induced alcohol-seeking. Neuropsychopharmacology. 2010; 35:783-791. [PubMed: 19924113]

Childress, AR.; Ehrman, R.; Rohsenow, D.; Robbins, SJ.; O’Brien, CP. Classically conditioned factors in drug dependence. In: Lowinson, J.; Millman, RP., editors. Comprehensive Textbook of Substance Abuse. Baltimore: Williams and Wilkins; 1993. p. 56-69.

Childress AR, Mozley PD, McElgin W, Fitzgerald J, Reivich M, O’Brien CP. Limbic activation during cue-induced cocaine craving. Am J Psychiatry. 1999; 156:11-18. [PubMed: 9892292]

Childress AR, Ehrman RN, Wang Z, Li Y, Sciortino N, Hakun J, Jens W, Suh J, Listerud J, Marquez K, Franklin T, Langleben D, Detre J, O'Brien CP. Prelude to passion: limbic activation by "unseen" drug and sexual cues. PLoS One. 2008; 3:e1506. [PubMed: 18231593]

Christoph GR, Leonzio RJ, Wilcox KS. Stimulation of the lateral habenula inhibits dopaminecontaining neurons in the substantia nigra and ventral tegmental area of the rat. J Neurosci. 1986; 6:613-619. [PubMed: 3958786]

Corbit LH, Balleine BW. The general and outcome-specific forms of Pavlovian-instrumental transfer are differentially mediated by the nucleus accumbens core and shell. Journal of Neuroscience. 2011; 31(33):11786-11794. [PubMed: 21849539]

Cullinan WE, Herman JP, Battaglia DF, Akil H, Watson SJ. Pattern and time course of immediate early gene expression in rat brain following acute stress. Neuroscience. 1995; 64:477-505. [PubMed: 7700534]

Danna CL, Elmer GI. Disruption of conditioned reward association by typical and atypical antipsychotics. Pharmacol Biochem Behav. 2010; 96(1):40-47. [PubMed: 20416333]

Day JJ, Carelli RM. The nucleus accumbens and Pavlovian reward learning. Neuroscientist. 2007; 13:148-159. [PubMed: 17404375]

Deutch AY, Bubser M, Young CD. Psychostimulant-induced Fos protein expression in the thalamic paraventricular nucleus. J Neurosci. 1998; 18:10680-10687. [PubMed: 9852603]

Di Ciano P, Everitt BJ. Dissociable effects of antagonism of NMDA and AMPA/KA receptors in the nucleus accumbens core and shell on cocaine-seeking behavior. Neuropsychopharmacology. 2001; 25:341-360. [PubMed: 11522463]

Di Ciano P, Cardinal RN, Cowell RA, Little SJ, Everitt BJ. Differential involvement of NMDA, AMPA/kainate, and dopamine receptors in the nucleus accumbens core in the acquisition and performance of pavlovian approach behavior. J Neurosci. 2001; 21:9471-9477. [PubMed: 11717381]

Di Filippo M, Picconi B, Tantucci M, Ghiglieri V, Bagetta V, Sgobio C, Tozzi A, Parnetti L, Calabresi P. Short-term and long-term plasticity at corticostriatal synapses: implications for learning and memory. Behav Brain Res. 2009; 199:108-118. [PubMed: 18948145]

Dickinson, A.; Balleine, B. Role of Learning in the operation of Motivational Systems. In: HP; RG, editors. Steven's Handbook of Experimental Psychology: Learning, Motivation and Emotion. New York: John Wiley \& Sons, Inc; 2002.

Everitt BJ, Robbins TW. Neural systems of reinforcement for drug addiction: from actions to habits to compulsion. Nat Neurosci. 2005; 8:1481-1489. [PubMed: 16251991]

Everitt BJ, Belin D, Economidou D, Pelloux Y, Dalley JW, Robbins TW. Review. Neural mechanisms underlying the vulnerability to develop compulsive drug-seeking habits and addiction. Philos Trans R Soc Lond B Biol Sci. 2008; 363:3125-3135. [PubMed: 18640910] 
Falck VG, Novelli MR, Wright NA, Alexander N. Gastric dysplasia: inter-observer variation, sulphomucin staining and nucleolar organizer region counting. Histopathology. 1990; 16:141-149. [PubMed: 2323735]

Fallon JH, Moore RY. Catecholamine innervation of the basal forebrain. IV. Topography of the dopamine projection to the basal forebrain and neostriatum. J Comp Neurol. 1978; 180:545-580. [PubMed: 659674]

Faure A, Richard JM, Berridge KC. Desire and dread from the nucleus accumbens: cortical glutamate and subcortical GABA differentially generate motivation and hedonic impact in the rat. PLoS One. 2010; 5:e11223. [PubMed: 20585461]

Flagel SB, Akil H, Robinson TE. Individual differences in the attribution of incentive salience to reward-related cues: Implications for addiction. Neuropharmacology. 2008a; 56(Suppl 1):139_ 148. [PubMed: 18619474]

Flagel SB, Watson SJ, Robinson TE, Akil H. Individual differences in the propensity to approach signals vs goals promote different adaptations in the dopamine system of rats. Psychopharmacology (Berl). 2007; 191:599-607. [PubMed: 16972103]

Flagel SB, Watson SJ, Akil H, Robinson TE. Individual differences in the attribution of incentive salience to a reward-related cue: influence on cocaine sensitization. Behav Brain Res. 2008b; 186:48-56. [PubMed: 17719099]

Flagel SB, Robinson TE, Clark JJ, Clinton SM, Watson SJ, Seeman P, Phillips PE, Akil H. An animal model of genetic vulnerability to behavioral disinhibition and responsiveness to reward-related cues: implications for addiction. Neuropsychopharmacology. 2010; 35:388-400. [PubMed: 19794408]

Flagel SB, Clark JJ, Robinson TE, Mayo L, Czuj A, Willuhn I, Akers CA, Clinton SM, Phillips PE, Akil H. A selective role for dopamine in stimulus-reward learning. Nature. 2011; 469:53-57. [PubMed: 21150898]

Franklin TR, Druhan JP. Expression of Fos-related antigens in the nucleus accumbens and associated regions following exposure to a cocaine-paired environment. Eur J Neurosci. 2000; 12:2097-2106. [PubMed: 10886349]

Franklin TR, Wang Z, Wang J, Sciortino N, Harper D, Li Y, Ehrman R, Kampman K, O’Brien CP, Detre JA, Childress AR. Limbic activation to cigarette smoking cues independent of nicotine withdrawal: a perfusion fMRI study. Neuropsychopharmacology. 2007; 32:2301-2309. [PubMed: 17375140]

Friedman A, Lax E, Dikshtein Y, Abraham L, Flaumenhaft Y, Sudai E, Ben-Tzion M, Ami-Ad L, Yaka R, Yadid G. Electrical stimulation of the lateral habenula produces enduring inhibitory effect on cocaine seeking behavior. Neuropharmacology. 2010; 59:452-459. [PubMed: 20600170]

Friedman A, Lax E, Dikshtein Y, Abraham L, Flaumenhaft Y, Sudai E, Ben-Tzion M, Yadid G. Electrical stimulation of the lateral habenula produces an inhibitory effect on sucrose selfadministration. Neuropharmacology. 2011; 60:381-387. [PubMed: 20955718]

Fuchs RA, Branham RK, See RE. Different neural substrates mediate cocaine seeking after abstinence versus extinction training: a critical role for the dorsolateral caudate-putamen. J Neurosci. 2006; 26:3584-3588. [PubMed: 16571766]

Fuchs RA, Evans KA, Parker MC, See RE. Differential involvement of the core and shell subregions of the nucleus accumbens in conditioned cue-induced reinstatement of cocaine seeking in rats. Psychopharmacology (Berl). 2004; 176:459-465. [PubMed: 15138757]

Graybiel AM, Aosaki T, Flaherty AW, Kimura M. The basal ganglia and adaptive motor control. Science. 1994; 265:1826-1831. [PubMed: 8091209]

Grilo CM, Shiffman S, Wing RR. Relapse crises and coping among dieters. J Consult Clin Psychol. 1989; 57:488-495. [PubMed: 2768608]

Groenewegen HJ, Berendse HW. The specificity of the 'nonspecific' midline and intralaminar thalamic nuclei. Trends Neurosci. 1994; 17:52-57. [PubMed: 7512768]

Guzowski JF. Insights into immediate-early gene function in hippocampal memory consolidation using antisense oligonucleotide and fluorescent imaging approaches. Hippocampus. 2002; 12:86-104. [PubMed: 11918292] 
Hamlin AS, Clemens KJ, Choi EA, McNally GP. Paraventricular thalamus mediates context-induced reinstatement (renewal) of extinguished reward seeking. Eur J Neurosci. 2009; 29:802-812. [PubMed: 19200064]

Hearst, E.; Jenkins, H. Monograph of the Psychonomic Society. Austin: 1974. Sign-tracking: the stimulus-reinforcer relation and directed action.

Hedreen JC, Bacon SJ, Price DL. A modified histochemical technique to visualize acetylcholinesterase-containing axons. J Histochem Cytochem. 1985; 33:134-140. [PubMed: 2578498]

Herkenham M, Nauta WJ. Afferent connections of the habenular nuclei in the rat. A horseradish peroxidase study, with a note on the fiber-of-passage problem. J Comp Neurol. 1977; 173:123146. [PubMed: 845280]

Hikosaka O. The habenula: from stress evasion to value-based decision-making. Nat Rev Neurosci. 2010; 11:503-513. [PubMed: 20559337]

Hong S, Jhou TC, Smith M, Saleem KS, Hikosaka O. Negative reward signals from the lateral habenula to dopamine neurons are mediated by rostromedial tegmental nucleus in primates. $\mathrm{J}$ Neurosci. 2011; 31(32):11457-11471. [PubMed: 21832176]

Igelstrom KM, Herbison AE, Hyland BI. Enhanced c-Fos expression in superior colliculus, paraventricular thalamus and septum during learning of cue-reward association. Neuroscience. 2010; 168:706-714. [PubMed: 20399252]

Ikemoto S. Brain reward circuitry beyond the mesolimbic dopamine system: a neurobiological theory. Neurosci Biobehav Rev. 2010; 35:129-150. [PubMed: 20149820]

Ito R, Hayen A. Opposing roles of nucleus accumbens core and shell dopamine in the modulation of limbic information processing. J Neurosci. 2011; 31:6001-6007. [PubMed: 21508225]

Ito R, Robbins TW, Everitt BJ. Differential control over cocaine-seeking behavior by nucleus accumbens core and shell. Nat Neurosci. 2004; 7:389-397. [PubMed: 15034590]

Ito R, Dalley JW, Robbins TW, Everitt BJ. Dopamine release in the dorsal striatum during cocaineseeking behavior under the control of a drug-associated cue. J Neurosci. 2002; 22:6247-6253. [PubMed: 12122083]

Ito R, Robbins TW, Pennartz CM, Everitt BJ. Functional interaction between the hippocampus and nucleus accumbens shell is necessary for the acquisition of appetitive spatial context conditioning. J Neurosci. 2008; 28:6950-6959. [PubMed: 18596169]

Jentsch JD, Taylor JR. Impulsivity resulting from frontostriatal dysfunction in drug abuse: implications for the control of behavior by reward-related stimuli. Psychopharmacology (Berl). 1999; 146:373390. [PubMed: 10550488]

Jhou TC, Geisler S, Marinelli M, Degarmo BA, Zahm DS. The mesopontine rostromedial tegmental nucleus: A structure targeted by the lateral habenula that projects to the ventral tegmental area of Tsai and substantia nigra pars compacta. J Comp Neurol. 2009; 513:566-596. [PubMed: 19235216]

Ji H, Shepard PD. Lateral habenula stimulation inhibits rat midbrain dopamine neurons through a GABA(A) receptor-mediated mechanism. J Neurosci. 2007; 27:6923-6930. [PubMed: 17596440]

Jones MW, Kilpatrick IC, Phillipson OT. Regulation of dopamine function in the nucleus accumbens of the rat by the thalamic paraventricular nucleus and adjacent midline nuclei. Exp Brain Res. 1989; 76:572-580. [PubMed: 2676574]

Kabbaj M, Akil H. Individual differences in novelty-seeking behavior in rats: a c-fos study. Neuroscience. 2001; 106:535-545. [PubMed: 11591454]

Kabbaj M, Devine DP, Savage VR, Akil H. Neurobiological correlates of individual differences in novelty-seeking behavior in the rat: differential expression of stress-related molecules. J Neurosci. 2000; 20:6983-6988. [PubMed: 10995843]

Kalivas PW, Volkow ND. The neural basis of addiction: a pathology of motivation and choice. Am J Psychiatry. 2005; 162:1403-1413. [PubMed: 16055761]

Kelley AE. Memory and addiction: shared neural circuitry and molecular mechanisms. Neuron. 2004; 44:161-179. [PubMed: 15450168]

Kelley AE, Schiltz CA, Landry CF. Neural systems recruited by drug- and food-related cues: studies of gene activation in corticolimbic regions. Physiol Behav. 2005a; 86:11-14. [PubMed: 16139315] 
Kelley AE, Baldo BA, Pratt WE. A proposed hypothalamic-thalamic-striatal axis for the integration of energy balance, arousal, and food reward. J Comp Neurol. 2005b; 493:72-85. [PubMed: 16255002]

Kluver H, Barrera E. A method for the combined staining of cells and fibers in the nervous system. $\mathbf{J}$ Neuropathol Exp Neurol. 1953; 12:400-403. [PubMed: 13097193]

Koob GF, Volkow ND. Neurocircuitry of addiction. Neuropsychopharmacology. 2010; 35:217-238. [PubMed: 19710631]

Kushner MG, Abrams K, Donahue C, Thuras P, Frost R, Kim SW. Urge to gamble in problem gamblers exposed to a casino environment. J Gambl Stud. 2007; 23:121-132. [PubMed: 17245663]

Lecourtier L, Kelly PH. Bilateral lesions of the habenula induce attentional disturbances in rats. Neuropsychopharmacology. 2005; 30:484-496. [PubMed: 15562296]

Lee EH, Huang SL. Role of lateral habenula in the regulation of exploratory behavior and its relationship to stress in rats. Behav Brain Res. 1988; 30:265-271. [PubMed: 3178997]

Lovic V, Saunders BT, Yager LM, Robinson TE. Rats prone to attribute incentive salience to reward cues are also prone to impulsive action. Behav Brain Res. 2011; 223(2):255-61. [PubMed: 21507334]

Lovinger DM. Neurotransmitter roles in synaptic modulation, plasticity and learning in the dorsal striatum. Neuropharmacology. 2010; 58:951-961. [PubMed: 20096294]

Luo AH, Tahsili-Fahadan P, Wise RA, Lupica CR, Aston-Jones G. Linking context with reward: A functional circuit from hippocampal CA3 to ventral tegmental area. Science. 2011; 333:353-356. [PubMed: 21764750]

Mahler SV, Berridge KC. Which cue to "want?" Central amygdala opioid activation enhances and focuses incentive salience on a prepotent reward cue. J Neurosci. 2009; 29:6500-6513. [PubMed: 19458221]

Matsumoto M, Hikosaka O. Lateral habenula as a source of negative reward signals in dopamine neurons. Nature. 2007; 447:1111-1115. [PubMed: 17522629]

McClernon FJ, Kozink RV, Lutz AM, Rose JE. 24-h smoking abstinence potentiates fMRI-BOLD activation to smoking cues in cerebral cortex and dorsal striatum. Psychopharmacology (Berl). 2009; 204:25-35. [PubMed: 19107465]

Mendoza J, Angeles-Castellanos M, Escobar C. Entrainment by a palatable meal induces foodanticipatory activity and c-Fos expression in reward-related areas of the brain. Neuroscience. 2005; 133:293-303. [PubMed: 15893651]

Mogenson GJ, Jones DL, Yim CY. From motivation to action: functional interface between the limbic system and the motor system. Prog Neurobiol. 1980; 14:69-97. [PubMed: 6999537]

Morrow JD, Maren S, Robinson TE. Individual variation in the propensity to attribute incentive salience to an appetitive cue predicts the propensity to attribute motivational salience to an aversive cue. Behav Brain Res. 2011; 220:238-243. [PubMed: 21316397]

Nakahara K, Fukui K, Murakami N. Involvement of thalamic paraventricular nucleus in the anticipatory reaction under food restriction in the rat. J Vet Med Sci. 2004; 66:1297-1300. [PubMed: 15528870]

Nishikawa T, Fage D, Scatton B. Evidence for, and nature of, the tonic inhibitory influence of habenulointerpeduncular pathways upon cerebral dopaminergic transmission in the rat. Brain Res. 1986; 373:324-336. [PubMed: 2424555]

O'Brien CP. Anticraving medications for relapse prevention: a possible new class of psychoactive medications. Am J Psychiatry. 2005; 162:1423-1431. [PubMed: 16055763]

O'Donohue W, Plaud JJ. The conditioning of human sexual arousal. Arch Sex Behav. 1994; 23:321344. [PubMed: 8024444]

Ostrander MM, Badiani A, Day HE, Norton CS, Watson SJ, Akil H, Robinson TE. Environmental context and drug history modulate amphetamine-induced c-fos mRNA expression in the basal ganglia, central extended amygdala, and associated limbic forebrain. Neuroscience. 2003; 120:551-571. [PubMed: 12890524]

Pavlov, I. Conditioned Reflexes: An Investigation of the Physiological Activity of the Cerebral Cortex. London: Oxford University Press; 1927. 
Paxinos, G.; Watson, C. The Rat Brain in Stereotaxic Coordinates. 2, 4. San Diego: Academic Press; 1998.

Potenza MN, Steinberg MA, Skudlarski P, Fulbright RK, Lacadie CM, Wilber MK, Rounsaville BJ, Gore JC, Wexler BE. Gambling urges in pathological gambling: a functional magnetic resonance imaging study. Arch Gen Psychiatry. 2003; 60:828-836. [PubMed: 12912766]

Rhodes JS, Crabbe JC. Gene expression induced by drugs of abuse. Curr Opin Pharmacol. 2005; 5:2633. [PubMed: 15661622]

Robbins TW, Everitt BJ. Drug addiction: bad habits add up. Nature. 1999; 398:567-570. [PubMed: 10217139]

Robinson TE, Berridge KC. The psychology and neurobiology of addiction: an incentive-sensitization view. Addiction. 2000; 95(Suppl 2):S91-117. [PubMed: 11002906]

Robinson TE, Flagel SB. Dissociating the predictive and incentive motivational properties of rewardrelated cues through the study of individual differences. Biol Psychiatry. 2009; 65:869-873. [PubMed: 18930184]

Saddoris MP, Stamatakis A, Carelli RM. Neural correlates of Pavlovian-to-instrumental transfer in the nucleus accumbens shell are selectively potentiated following cocaine self-administration. Eur J Neurosci. 2011; 33:2274-2287. [PubMed: 21507084]

Sanchez-Gonzalez MA, Garcia-Cabezas MA, Rico B, Cavada C. The primate thalamus is a key target for brain dopamine. J Neurosci. 2005; 25:6076-6083. [PubMed: 15987937]

Saunders BT, Robinson TE. A cocaine cue acts as an incentive stimulus in some but not others: implications for addiction. Biol Psychiatry. 2010; 67:730-736. [PubMed: 20045508]

Schachter S. Obesity and eating. Internal and external cues differentially affect the eating behavior of obese and normal subjects. Science. 1968; 161:751-756. [PubMed: 5663800]

Schilman EA, Uylings HB, Galis-de Graaf Y, Joel D, Groenewegen HJ. The orbital cortex in rats topographically projects to central parts of the caudate-putamen complex. Neurosci Lett. 2008; 432:40-45. [PubMed: 18248891]

Schiltz CA, Bremer QZ, Landry CF, Kelley AE. Food-associated cues alter forebrain functional connectivity as assessed with immediate early gene and proenkephalin expression. BMC Biol. 2007; 5:16. [PubMed: 17462082]

Schoenbaum G, Shaham Y. The role of orbitofrontal cortex in drug addiction: a review of preclinical studies. Biol Psychiatry. 2008; 63:256-262. [PubMed: 17719014]

Schultz W. Predictive reward signal of dopamine neurons. J Neurophysiol. 1998; 80:1-27. [PubMed: 9658025]

Schultz W, Dayan P, Montague PR. A neural substrate of prediction and reward. Science. 1997; 275:1593-1599. [PubMed: 9054347]

See RE, Elliott JC, Feltenstein MW. The role of dorsal vs ventral striatal pathways in cocaine-seeking behavior after prolonged abstinence in rats. Psychopharmacology (Berl). 2007; 194:321-331. [PubMed: 17589830]

Sellings LH, Clarke PB. Segregation of amphetamine reward and locomotor stimulation between nucleus accumbens medial shell and core. J Neurosci. 2003; 23:6295-6303. [PubMed: 12867514]

Shiflett MW, Balleine BW. Molecular substrates of action control in cortico-striatal circuits. Prog Neurobiol. 2011 In press.

Smith-Roe SL, Kelley AE. Coincident activation of NMDA and dopamine D1 receptors within the nucleus accumbens core is required for appetitive instrumental learning. J Neurosci. 2000; 20:7737-7742. [PubMed: 11027236]

Smith KS, Berridge KC, Aldridge JW. Disentangling pleasure from incentive salience and learning signals in brain reward circuitry. Proc Natl Acad Sci U S A. 2011; 108:E255-264. [PubMed: 21670308]

Smith KS, Tindell AJ, Aldridge JW, Berridge KC. Ventral pallidum roles in reward and motivation. Behav Brain Res. 2009; 196:155-167. [PubMed: 18955088]

Sobik L, Hutchison K, Craighead L. Cue-elicited craving for food: a fresh approach to the study of binge eating. Appetite. 2005; 44:253-261. [PubMed: 15876472] 
Surmeier DJ, Plotkin J, Shen W. Dopamine and synaptic plasticity in dorsal striatal circuits controlling action selection. Curr Opin Neurobiol. 2009; 19:621-628. [PubMed: 19896832]

Sutherland RJ. The dorsal diencephalic conduction system: a review of the anatomy and functions of the habenular complex. Neurosci Biobehav Rev. 1982; 6:1-13. [PubMed: 7041014]

Tiffany ST. A cognitive model of drug urges and drug-use behavior: role of automatic and nonautomatic processes. Psychol Rev. 1990; 97:147-168. [PubMed: 2186423]

Toates F. The interaction of cognitive and stimulus-response processes in the control of behaviour. Neurosci Biobehav Rev. 1998; 22:59-83. [PubMed: 9491940]

Tzingounis AV, Nicoll RA. Arc/Arg3.1: linking gene expression to synaptic plasticity and memory. Neuron. 2006; 52:403-407. [PubMed: 17088207]

Van der Werf YD, Witter MP, Groenewegen HJ. The intralaminar and midline nuclei of the thalamus. Anatomical and functional evidence for participation in processes of arousal and awareness. Brain Res Brain Res Rev. 2002; 39:107-140. [PubMed: 12423763]

Verbeke, G.; Molenberghs, G. Linear Mixed Models for Longitudinal Data. New York: Springer; 2000.

Volkow ND, Wang GJ, Telang F, Fowler JS, Logan J, Childress AR, Jayne M, Ma Y, Wong C. Cocaine cues and dopamine in dorsal striatum: mechanism of craving in cocaine addiction. $\mathrm{J}$ Neurosci. 2006; 26:6583-6588. [PubMed: 16775146]

Volkow ND, Wang GJ, Fowler JS, Logan J, Jayne M, Franceschi D, Wong C, Gatley SJ, Gifford AN, Ding YS, Pappas N. "Nonhedonic" food motivation in humans involves dopamine in the dorsal striatum and methylphenidate amplifies this effect. Synapse. 2002; 44:175-180. [PubMed: 11954049]

Volkow ND, Wang GJ, Fischman MW, Foltin RW, Fowler JS, Abumrad NN, Vitkun S, Logan J, Gatley SJ, Pappas N, Hitzemann R, Shea CE. Relationship between subjective effects of cocaine and dopamine transporter occupancy. Nature. 1997; 386:827-830. [PubMed: 9126740]

Voorn P, Vanderschuren LJ, Groenewegen HJ, Robbins TW, Pennartz CM. Putting a spin on the dorsal-ventral divide of the striatum. Trends Neurosci. 2004; 27:468-474. [PubMed: 15271494]

Waelti P, Dickinson A, Schultz W. Dopamine responses comply with basic assumptions of formal learning theory. Nature. 2001; 412:43-48. [PubMed: 11452299]

Weiss F. Neurobiology of craving, conditioned reward and relapse. Curr Opin Pharmacol. 2005; 5:919. [PubMed: 15661620]

White NM, McDonald RJ. Multiple parallel memory systems in the brain of the rat. Neurobiol Learn Mem. 2002; 77:125-184. [PubMed: 11848717]

Winstanley CA. The orbitofrontal cortex, impulsivity, and addiction: probing orbitofrontal dysfunction at the neural, neurochemical, and molecular level. Ann N Y Acad Sci. 2007; 1121:639-655. [PubMed: 17846162]

Woods SC, Hutton RA, Makous W. Conditioned insulin secretion in the albino rat. Proc Soc Exp Biol Med. 1970; 133:964-8. [PubMed: 4907937]

Yager LM, Robinson TE. Cue-induced reinstatement of food seeking in rats that differ in their propensity to attribute incentive salience to food cues. Behav Brain Res. 2010; 214:30-34. [PubMed: 20416342]

Yamaguchi T, Wang HL, Li X, Ng TH, Morales M. Mesocorticolimbic glutamatergic pathway. J Neurosci. 2011; 31:8476-8490. [PubMed: 21653852]

Young CD, Deutch AY. The effects of thalamic paraventricular nucleus lesions on cocaine-induced locomotor activity and sensitization. Pharmacol Biochem Behav. 1998; 60:753-758. [PubMed: 9678661]

Zavala AR, Osredkar T, Joyce JN, Neisewander JL. Upregulation of Arc mRNA expression in the prefrontal cortex following cue-induced reinstatement of extinguished cocaine-seeking behavior. Synapse. 2008; 62:421-431. [PubMed: 18361437]

Zellner MR, Ranaldi R. How conditioned stimuli acquire the ability to activate VTA dopamine cells: a proposed neurobiological component of reward-related learning. Neurosci Biobehav Rev. 2010; 34:769-780. [PubMed: 19914285] 


\section{Highlights}

Individuals respond differently to reward cues.

Reward cues can act as predictors and/or incentive stimuli.

What brain regions are engaged when a cue has incentive vs predictive value?

The predictive value of a reward cue is not sufficient to engage brain reward systems.

Brain reward systems are only engaged when reward cues are incentive stimuli. 


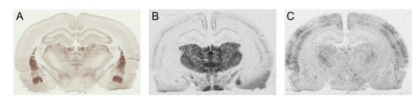

Figure 1.

Representative images used to guide quantification of brain regions of interest and processed for in situ hybridization. A) Acetylcholinesterase staining was performed on sections adjacent to those processed for c-fos mRNA and served as a guide to identify nuclei of the amygdala. B) Tissue processed for vglut- 2 mRNA to identify thalamic and habenular nuclei. C) Representative image of tissue processed for c-fos mRNA using in situ hybridization. 


\section{Approach Index}

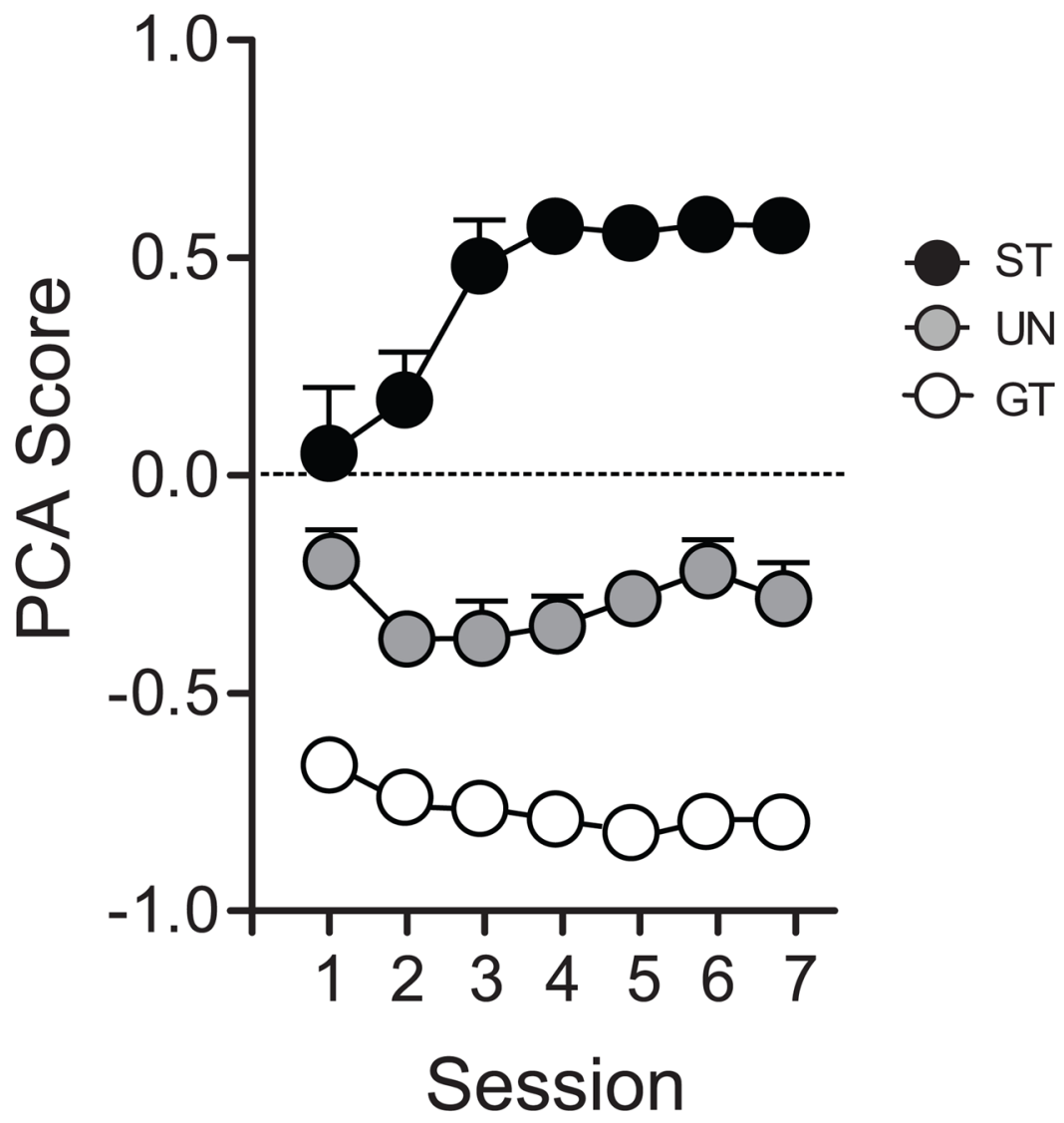

Figure 2.

Mean + SEM Pavlovian Conditioned Approach scores across 7 days of Pavlovian training for STs $(n=6)$, GTs $(n=10)$ and rats in the unpaired group that received pseudorandom presentation of the CS and US (UN, n=9). A PCA score of +1 means all responses were directed towards the lever-CS, a score of -1 indicates that all responses were directed away from the lever-CS and towards the food cup, and a score of zero indicates that responses were directed equally to both places. 


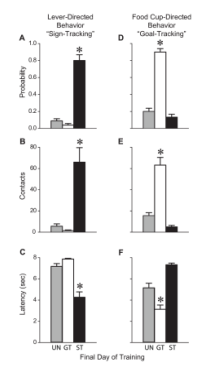

\section{Figure 3.}

Lever-CS directed behavior (sign-tracking) and food cup directed behavior (goal-tracking) during the CS period on the final day of Pavlovian training in GTs $(n=10)$, STs $(n=6)$ and the Unpaired (UN) group ( $n=9$ ). Mean + SEM for, A) probability of approach towards the lever-CS, B) number of contacts with the lever-CS, C) latency to contact the lever-CS, D) probability of approach towards the food cup, E) number of contacts with the food cup during lever-CS presentation, and F) latency to contact the food cup once the lever-CS was presented. Relative to UN and GT rats, STs approached the lever-CS more frequently and rapidly, and engaged it more avidly (A-C, post-hoc comparisons, ${ }^{*} \mathrm{P}<0.0001$ ). In contrast, GTs approached the food cup more frequently and rapidly, and engaged it more avidly than UN and ST rats (D-F, post-hoc comparisons, $\left.{ }^{*} \mathrm{P}<0.001\right)$. 


\section{Prefrontal Cortex}

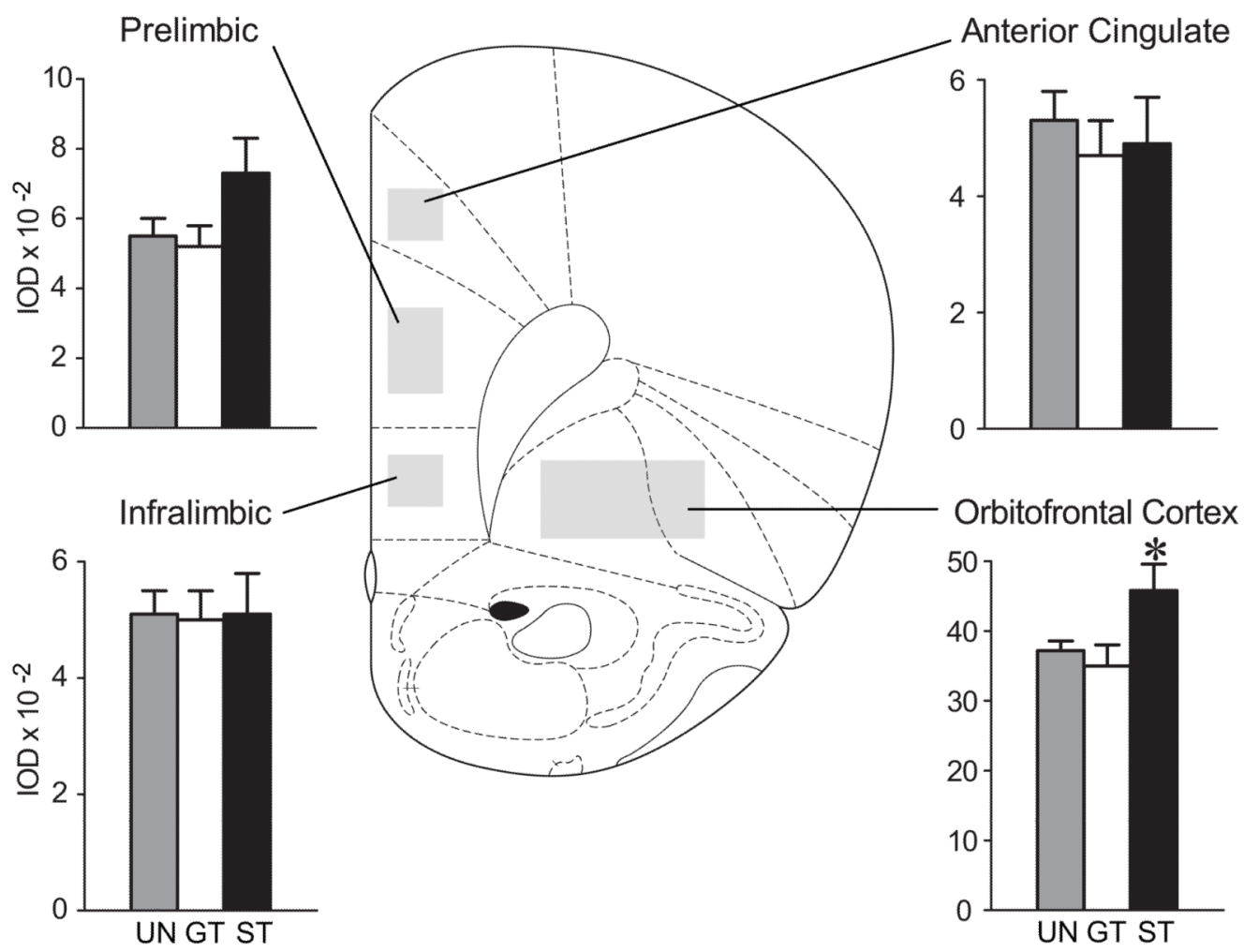

Figure 4.

Mean + SEM of integrated optical density (IOD) values for c-fos mRNA in prefrontal cortical regions. Representative atlas image from A-P level $3.2 \mathrm{~mm}$ anterior to bregma (Paxinos and Watson, 1998). STs $(n=6)$ had increased c-fos expression in the orbitofrontal cortex relative to $\mathrm{UN}(\mathrm{n}=9)$ and GT $(\mathrm{n}=10)$ groups (post-hoc comparisons, $* \mathrm{P} \leq 0.05)$. 


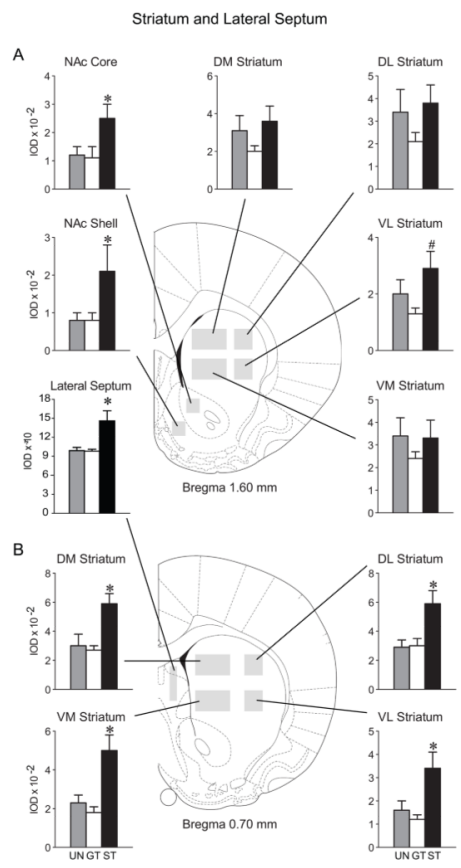

Figure 5.

Mean + SEM of integrated optical density (IOD) values for c-fos mRNA in A) rostral regions of the striatum and the lateral septum and $\mathrm{B}$ ) more posterior portions of the striatum. Abbreviations: NAc $=$ nucleus accumbens, $\mathrm{DM}=$ dorsomedial, $\mathrm{DL}=$ dorsolateral, $\mathrm{VM}=$ ventromedial, $\mathrm{VL}=$ ventrolateral. Representative atlas images are shown for A) A-P level $1.6 \mathrm{~mm}$ and B) A-P level $0.7 \mathrm{~mm}$ anterior to bregma (Paxinos and Watson, 1998). For the more anterior section (A) post-hoc comparisons revealed that STs $(n=6)$ showed greater cfos mRNA expression relative to UN $(n=9)$ and GT $(n=10)$ groups in the NAc core, NAc shell and the lateral septum $(* \mathrm{P}<0.04)$. In the rostral portion of the VL striatum, STs exhibit greater expression than GTs (post-hoc comparison, ${ }^{\#} \mathrm{P}=0.01$ ). At the more posterior level (B) STs showed greater c-fos mRNA expression than both GTs and the UN group in the DM striatum, DL striatum, VM striatum and VL striatum (post-hoc comparisons, $* \mathrm{P}<0.01$ ). 
Habenula and Thalamus

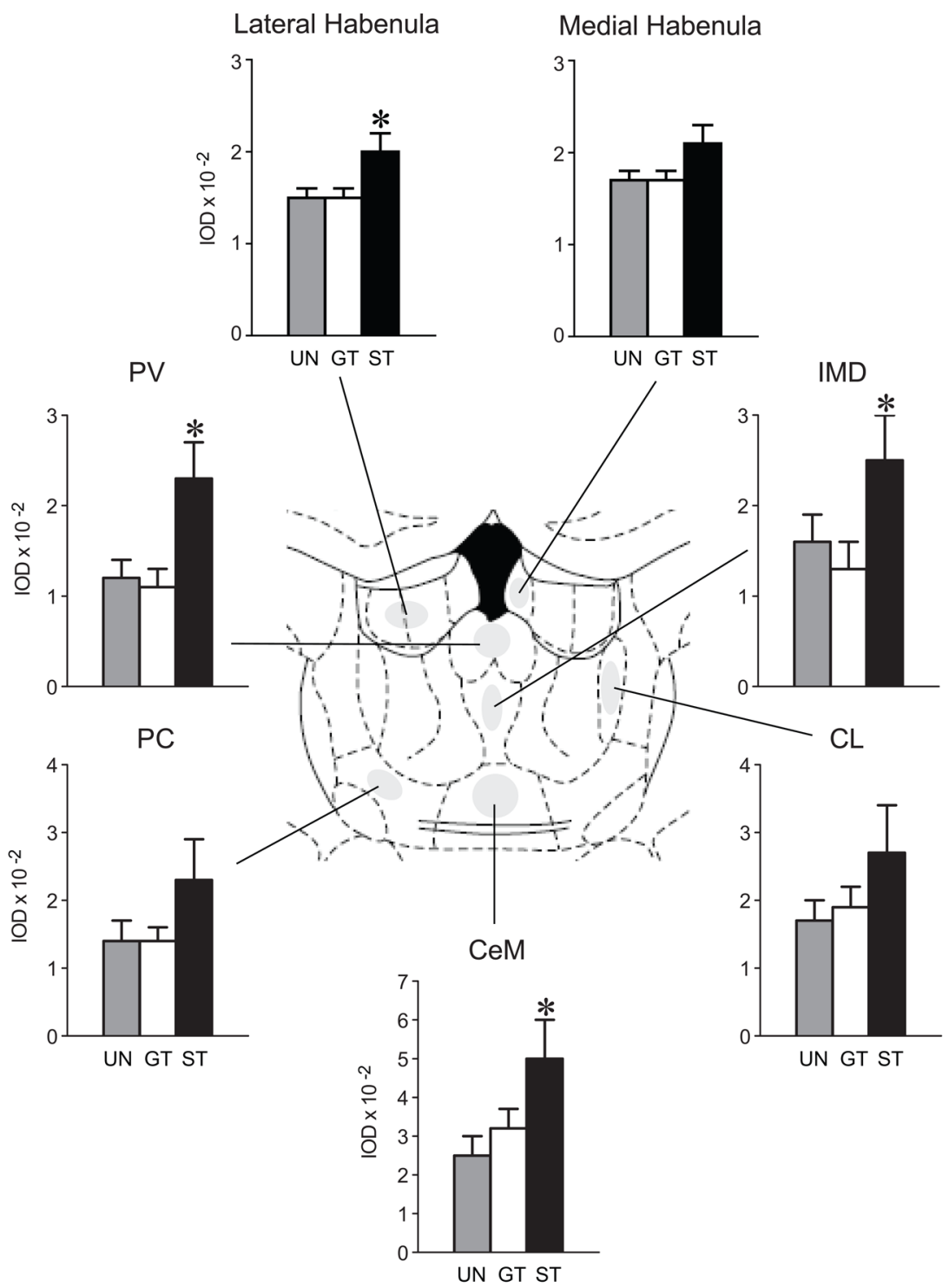

Figure 6.

Mean + SEM optical density (IOD) values for c-fos mRNA in the habenula and thalamus. Abbreviations: $\mathrm{PVT}=$ paraventricular nucleus of the thalamus, $\mathrm{IMD}=$ intermediodorsal nucleus of the thalamus, $\mathrm{PC}=$ paracentral nucleus of the thalamus, $\mathrm{CeM}=$ central medial nucleus of the thalamus, $\mathrm{CL}=$ central lateral nucleus of the thalamus. Representative atlas image from A-P level $-3.3 \mathrm{~mm}$ posterior to bregma. STs $(\mathrm{n}=6)$ showed greater $\mathrm{c}$-fos expression in the lateral habenula and the PVT nucleus of the thalamus compared to UN $(\mathrm{n}=9)$ and $\mathrm{GT}(\mathrm{n}=10)$ groups (post-hoc comparisons, $\left.{ }^{*} \mathrm{P} \leq 0.005\right)$. STs also showed greater expression in the IMD and CEM nuclei of the thalamus, but post-hoc comparisons revealed that these effects were only significant relative to GTs in the IMD nucleus ( $\left.{ }^{\#} \mathrm{P}=0.02\right)$ and to the UN group in the CEM nucleus $\left({ }^{\Psi} \mathrm{P}=0.01\right)$. 


\section{Amygdala}
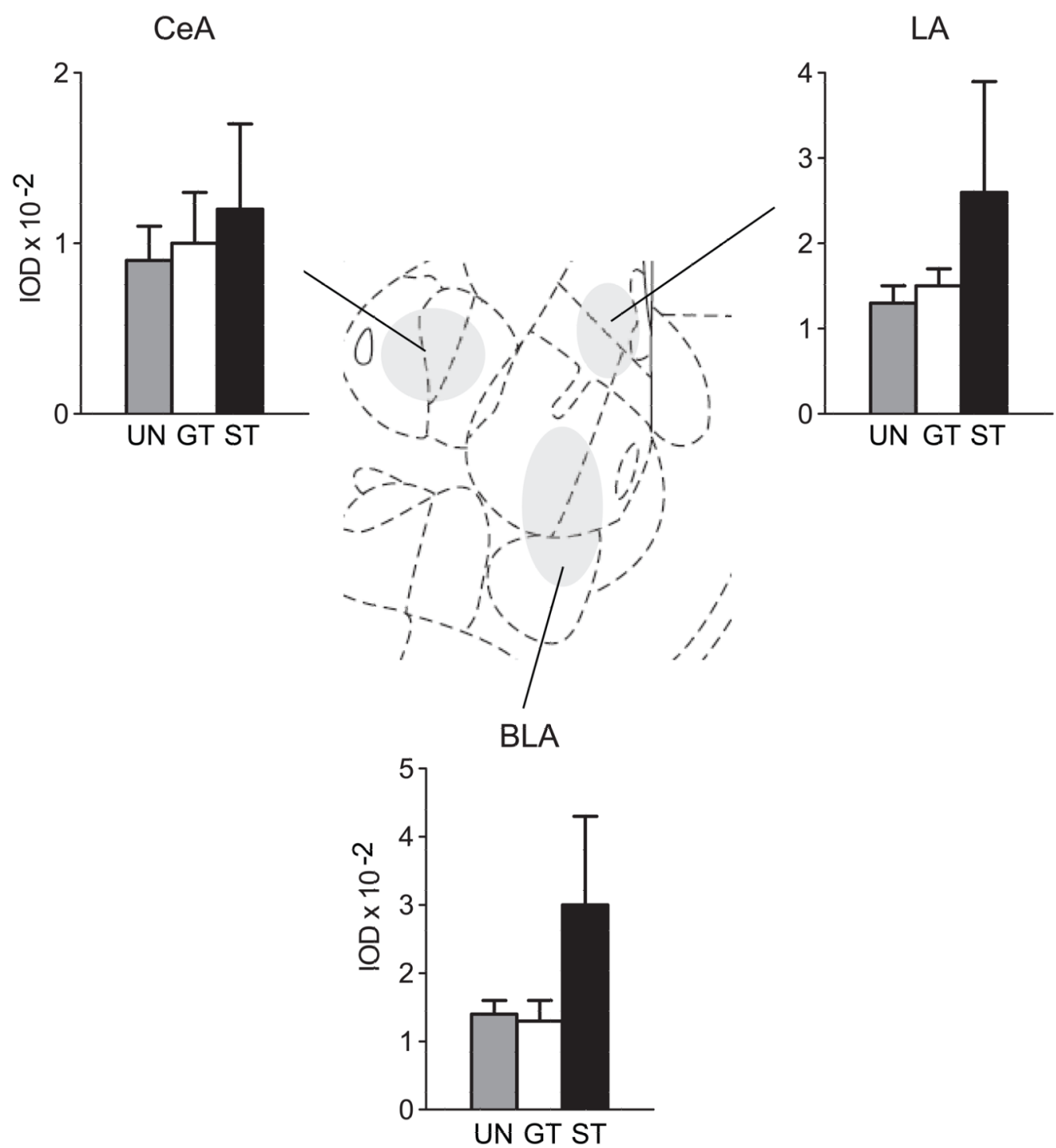

Figure 7.

Mean + SEM optical density (IOD) values for c-fos mRNA in the amygdala for STs $(n=5)$, GTs $(n=10)$ and UN $(n=9)$. Abbreviations: CeA = central nucleus of the amygdala, LA = lateral nucleus of the amygdala and BLA = basolateral nucleus of the amygdala.

Representative atlas image from A-P level $-2.56 \mathrm{~mm}$ posterior to bregma. There were no significant group differences in c-fos expression in the amygdala. 


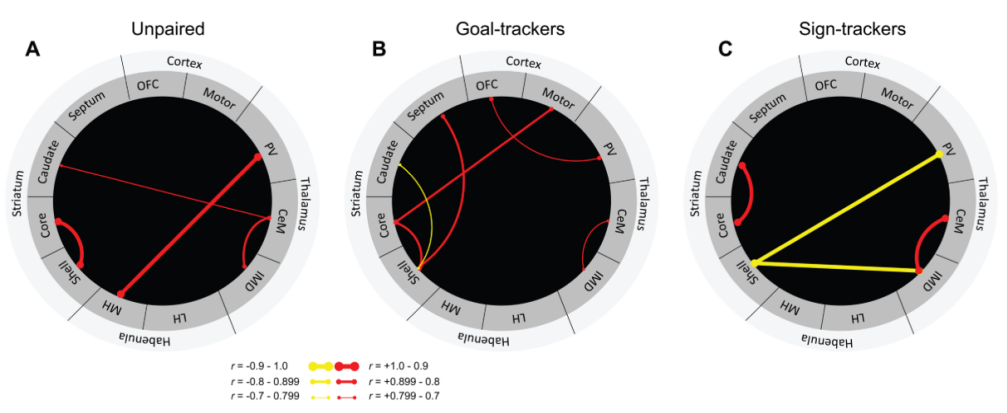

\section{Figure 8.}

These diagrams illustrate pairs of brain regions in which there was a significant relationship in patterns of c-fos mRNA expression as indicated by highly correlated levels of expression for A) unpaired group, B) goal-trackers and C) sign-trackers. Red lines indicate significant positive correlations between brain regions and yellow lines represent negative correlations. The thickness of the line reflects the strength of the correlation. Abbreviations: OFC $=$ orbitofrontal cortex , Motor $=$ primary motor cortex, $\mathrm{PVT}=$ paraventricular nucleus of the thalamus, $\mathrm{CeM}=$ central medial nucleus of the thalamus, $\mathrm{IMD}=$ intermediodorsal nucleus of the thalamus, $\mathrm{LH}=$ lateral habenula, $\mathrm{MH}=$ medial habenula, Shell $=$ shell of the nucleus accumbens, Core $=$ core of the nucleus accumbens, Caudate $=$ caudate nucleus of the striatum (restricted to posterior levels), Septum = lateral septum. 


\section{Table 1}

This table lists the correlation coefficient ( $r$ ), calculated P-value, and "q-value" for the significant correlations included in Figure 8. The "q-value" was generated from the list of p-values and multiplied by 100 to illustrate the chance for false positives to occur for a given correlation. Only correlations with less than a $10 \%$ chance for false positives are included. The data are listed by the strength of the correlation (in descending order) for each group separately. Abbreviations Abbreviations: IMD = intermediodorsal nucleus of the thalamus, $\mathrm{CeM}=$ central medial nucleus of the thalamus, DL Caudate $=$ dorsolateral portion of the posterior caudate, VM

Caudate $=$ ventromedial portion of the posterior caudate, $\mathrm{PVT}=$ paraventricular nucleus of the thalamus, $\mathrm{MH}$ $=$ medial habenula , Core $=$ core of the nucleus accumbens, Shell $=$ shell of the nucleus accumbens, Septum $=$ lateral septum, $\mathrm{OFC}=$ orbitofrontal cortex.

\begin{tabular}{|l|c|c|c|}
\hline Correlated Brain Regions & $\boldsymbol{r}$ & P-value & q-value (x 100) \\
\hline Unpaired Group & & & \\
\hline Core - Shell & 0.94 & $<0.0001$ & 0.21 \\
\hline PV - MH & 0.92 & $<0.0001$ & 0.53 \\
\hline VM Caudate - Primary Motor & 0.92 & 0.002 & 1.16 \\
\hline DL Caudate - Primary Motor & 0.87 & 0.008 & 4.61 \\
\hline IMD - CeM & 0.87 & 0.001 & 1.02 \\
\hline Goal-trackers & & & \\
\hline Shell - Septum & 0.90 & 0.001 & 2.51 \\
\hline Core - Primary Motor & 0.85 & 0.002 & 3.29 \\
\hline Core - Shell & 0.84 & 0.001 & 2.51 \\
\hline OFC - PV & 0.75 & 0.010 & 9.19 \\
\hline IMD - CeM & 0.74 & 0.012 & 9.19 \\
\hline Shell - DM Caudate & -0.74 & 0.012 & 9.19 \\
\hline Sign-trackers & & & \\
\hline Shell - IMD & -0.93 & 0.005 & 6.67 \\
\hline Shell - PV & -0.93 & 0.005 & 6.67 \\
\hline IMD - CeM & 0.91 & 0.005 & 8.30 \\
\hline Core - DM Caudate & 0.90 & 0.009 & 8.30 \\
\hline
\end{tabular}

